\title{
Fatigue Crack Propagation Monitoring Using Fibre Bragg Grating Sensors
}

\author{
Magdalena Mieloszyk (D)
}

Institute of Fluid Flow Machinery, Polish Academy of Sciences, 80-231 Gdańsk, Poland; mmieloszyk@imp.gda.pl

\begin{abstract}
The paper presents the analysis of the possibility of fatigue crack detection and monitoring its propagation process using fibre Bragg grating (FBG) sensors. The investigations were carried out on an aluminium alloy sample (a part of the Mi-2 helicopter rotor blade). During the fatigue test, the sample was equipped with FBG sensors applied for strain measurement and the vibration-based strain monitoring. It was observed that the strain curves determined by the FBG sensors agreed well with the fatigue force profile. However, the strain curves were almost insensitive to the crack propagation process, except in the last stage of the test, when the crack length was equal to $25 \mathrm{~mm}$. The strain values and the natural frequencies of the sample that were determined experimentally were compared with the values achieved from the finite element method model, with both methods showing good agreement. Additionally, spectrogram-based analyses were performed, focused on the acoustic waves phenomena related to a crack propagation process. It was confirmed that the proposed signal processing method, based on spectrogram analyses, can be applied for the detection of fatigue crack development in metal structures.
\end{abstract}

Keywords: fatigue crack; fibre bragg grating sensors; FBG; blade; structural health monitoring; vibration

Citation: Mieloszyk, M. Fatigue Crack Propagation Monitoring Using Fibre Bragg Grating Sensors. Vibration 2021, 4, 700-721. https://doi.org/ 10.3390/vibration4030039

Academic Editor: César M. A. Vasques

Received: 31 March 2021

Accepted: 2 September 2021

Published: 3 September 2021

Publisher's Note: MDPI stays neutral with regard to jurisdictional claims in published maps and institutional affiliations.

\section{Introduction}

Fatigue wear and corrosion are two of the most typical processes that occur during the normal exploitation of aircraft structures. The airplanes are investigated using NDT (Non-destructive testing) techniques. The typical NDT methods used for aircraft structures are: visual inspection without/with a penetrative agent, ultrasound inspection, X-ray inspection, eddy current, acoustic emission and infrared thermography [1,2]. However, NDT techniques, mentioned above, cannot be used for in-flight monitoring of aircraft structures.

The high complexity and costs of aircraft structures, combined with their high operational reliability and safety needs, result in an increasing interest in Structural Health Monitoring (SHM) systems. Fibre Bragg grating (FBG) sensors are a very interesting tool for SHM applications. In SHM systems, FBG sensors are mostly applied for strain [3], and temperature [4] measurements. The most important advantages of FBG sensors are their small size, high multiplexing capabilities, corrosion resistance, and lack of calibration needs [5]. FBG sensors can be mounted on structure surfaces [6-8], as well as embedded into the material during its manufacturing $[9,10]$. At present, FBG sensors are integral parts of the SHM systems installed on different structures: bridges [10], offshore platforms [11-13], buildings [14-16], marine vessels $[9,17,18]$. In aircraft structures, FBG sensors are mostly used to monitor fuselage parts [19-21], aircraft cockpit [6] or composite wings [22-24].

In cyclic-loaded metallic structures, such as rotor blades, small cracks gradually develop, and any crack with a stress intensity factor exceeding the fracture toughness can lead to catastrophic failure. The stress intensity factor depends on both crack length and applied stress [25]. Therefore, inspection techniques able to detect small fatigue cracks and monitor their propagation process are crucial to ensure the reliability of metallic aircraft 
structures. An SHM system based on FBG sensors bonded to military aircraft structures should retain functionality over the design life of the airframe. Typically, this is over 30,000 flight hours (15-20 years) [26].

A variety of complex signals collected by a large number of sensors creating SHM systems require good post-processing algorithms, facilitating data analysis. Examples of such algorithms are: multiple signal classification (MUSIC) and the reconstruction algorithm for probabilistic inspection of damage (RAPID). MUSIC is a method used to address the Rayleigh criterion [27] and has been applied to a variety of guided wave-based SHM systems. Zhong et al. [28] applied the MUSIC algorithm to distinguish multiple damage on a carbon-fibre-reinforced polymer (CFRP) plate and a real aircraft composite oil tank. Fan et al. [27] proposed a modification of MUSIC, combining the adaptive focusing of the time reversal algorithm and the high resolution of direction estimation of the MUSIC algorithm. The modified MUSIC algorithm was applied for the SHM system based on Lamb waves for damage (drilled holes) detection in aluminium plate-type aircraft structures [27]. Bao et al. [29] proposed another modification to the MUSIC algorithm that overcomes the problems related to the low signal-to-noise ratio (SNR) of damage scattered signals, as well as the structural anisotropy in complex elements that limits the localisation ability of the algorithm. They developed a new aperture-MUSIC algorithm for damage diagnosis with array error compensation. Its effectiveness in detecting corrosion damage was successfully verified on a complex aircraft structure with T-stiffeners, ribs and rivets [29]. RAPID is based on a comparison between the obtained signals and a damage probability distribution [30]. Zhao et al. [31] applied the RAPID algorithm for damage detection in a real aluminium wing specimen using Lamb waves. Azuara et al. [30] presented a geometrical modification of the standard RAPID algorithm, allowing for a more accurate location of the damage (due to impact) in a fibre-reinforced polymer plate using Lamb waves. Briand et al. [32] compared a few damage localisation methods for damage detection in a CFRP plate equipped with a stiffener and a piezoelectric sensor-actuator network. The RAPID algorithm showed very promising results in the determination of the predicted damage size using Lamb waves.

FBG sensors are used for the SHM of structures subjected to long-term fatigue loads, to confirm that the material of the sensors is able to withstand the fatigue conditions. At present, investigations focus on FBG sensors' utility in fatigue and fracture mechanics, including fatigue crack propagation. Ang et al. [33] analysed the fatigue properties of an uncoated FBG sensor bonded to the CFRP substrate as a representative of aircraft composite structure. The influence of two main stripped methods (mechanical and chemical) on the fatigue properties of fibre optics sensors was evaluated under cyclic tension-tension loading. The signal quality of FBG sensors degraded due to the formation of sub-critical cracks within the fibre by stress corrosion. Based on the S-N curve, a fatigue endurance limit (at $10^{6}$ load cycles) was determined as $3500 \mu \epsilon$, below which fibres have an infinite fatigue life and there is no degradation to the FBG sensor signal quality [33].

Yashiro and Okabe [34] used FBG sensors for damage detection and localisation in holed CFRP laminates under cyclic loading. Any cracks and delaminations and there influence on the reflected spectrum from FBG sensors were easily identified. Takeda et al. [35] applied FBG sensors to durability tests of a composite wing structure. This investigation included fatigue tests based on the design service life of the analysed aircraft panel. During the test, damaged from impact does not evolve. Therefore, strain-monitoring using FBG sensors does not indicate any remarkable changes due to damage evolution. Kocaman et al. [36] analysed the reliability and durability of FBG sensors embedded into glass-fibre-reinforced polymer (GFRP) subjected to fatigue loading. It was observed that the strain inequality along the fibre length can result in FBG sensor spectrum distortion. Such a phenomenon can occur due to crack development or the angle between the sensor axis and the fibre reinforcement. Shen et al. [37] analysed the possibility of applying an FBG sensor rosette to strain-monitoring in a ship hull during its operation. The analysis also contains a fatigue-loading influence analysis of the sensor itself, as well as its impact on the 
metal sample with the attached sensor. The analyses were performed in an environment with a high humidity level and in salt water. Linearity between the wavelength change and loading was observed for all analysed cases, confirming the good stability of FBG sensors. Szebenyi et al. [38] demonstrated the applicability of FBG sensors embedded into flax-fibre-reinforced polymer under fatigue loading. The experimental investigation suggested that such a measurement set-up can be applied to monitoring of the cyclic creep strain of the composites. Vieira et al. [39] developed a laboratory prototype of a weightmeasuring system based on FBG sensors embedded in a silicone rubber tray. The proposed solution considered the need for removal of the environmental temperature influence on the system structure. The experimental investigation showed the good repeatability of the system, confirming its utility for accurate small-weight measurement (up to $500 \mathrm{~g}$ ). A linear response of the embedded FBG sensors was observed in this loading range. Ruzek et al. [20] and Tserpes et al. [21] performed experimental and numerical analyses of CFRP fuselage stiffened panels with FBG sensors arrays. Among the many analyses, the possibility of applying the FBG sensors to strain measurement during fatigue loading and damage detection was considered, to validate of the utility of the sensors. Liu et al. [11] analysed the utility of FBG sensors embedded into a composite material (in a form of a package) and attached to a wind turbine blade for the strain variation monitoring under static and fatigue tests. It was observed that the parameters (length, thickness) of the joint between the package and the blade strongly influenced the strain transfer efficiency. FBG sensors can be applied for strain measurements under both static and suddenly applied load.

The investigations presented above indicate both the need for the development of methods of fatigue crack propagation monitoring in aircraft structures and the possibility of the application of FBG-based SHM systems for this purpose. Their main advantages in such an application are the lack of electricity in the measurement array, combined with the small size and low weight of the sensors. Additionally, the FBG sensors are very sensitive to even very small changes in local strain. The experimental (and numerical) analyses were focused on the possibility of applying FBG sensors to fatigue crack propagation in a metallic aircraft structure. The novelty of the study is its complex analysis of the utility of FBG strain sensors in vibration-based analyses, leading to the determination of consecutive stages of a fatigue crack propagation process during a fatigue test.

The paper is structured as follows. Firstly, the investigated structure and the measurement set-up are described. Secondly, the experimental and numerical investigation results are presented and discussed. Finally, the conclusions are drawn.

\section{Main Rotor Blade}

\subsection{Fatigue Cracks in Main Rotor Blades}

A helicopter main rotor system is a rotating part consisting of a mast, a hub, and two or more rotor blades. The mast is a hollow cylindrical metal shaft that extends upwards and is driven by the transmission. The system is used for lift generation [40].

Helicopter rotor blades are loaded by a force changing in time. In the case of any fatigue damage, the possibility of destroying a blade is very high. Cases of throwing away rotor blades during the flight due to fatigue damage were observed [41]. Such accidents result in flight catastrophe in which not only is the helicopter completely destroyed, but the crew are also in danger. It should be underlined that, even in the case of both engines failing, the main rotor can save the helicopter due to the auto-rotation phenomenon.

Helicopter main rotor blades operate under alternating loads, which can induce fatigue cracking. Typically, using the normal inspection methods, the critical crack length for a rotor blade can be too small to detect prior to failure. A safe life for retirement time will generally be given in both flight hours and chronological age. However, there are uncertainties in the prediction of main rotor blade operational loads due to factors such as: variations in the operating speeds and loads at low speed, interactions with the environment, accidental damage occurrence as a result of impact (e.g., stone, hail) and chemical influence as well as atmospheric processes (corrosion). These factors create 
uncertainties in the prediction of load spectra and fatigue growth and, consequently, the retirement time of the rotor blades needs to be calculated to provide a large margin of safety [26].

A helicopter's main rotor blades are complex structures. In helicopter Mi-2, this element is made of aluminium alloy (duraluminium 2024-T3). The honeycomb filler has regular hexagonal cells of $5 \mathrm{~mm}$ size. The scheme of a main rotor blade part is presented in Figure 1. In the scheme, three regions are marked according to their structural features. They are as follows:

(1) A leading edge part including corrosion protection elements and heating parts;

(2) A middle part including upper and lower D-spar walls;

(3) A back part containing a D-spar back wall as well as additional sections with honeycomb filler (do not present in the scheme).

Investigations performed on rotor blades of helicopters Mi-2, Mi-4, Mi-8 and Mi-24 suggest that the origin of many fatigue cracks is located on the back wall of the main rotor blade D-spar (73\% cases) (region (3) - Figure 1). Then, the cracks propagate on upper or lower walls of a D-spar (region (2) - Figure 1). The dimension of typical fatigue damage ranges from $35 \%$ to $40 \%$ of an area of a blade cross-section. Usually, damaged areas are detected during typical scheduled NDT inspections, and blades are repaired [41].

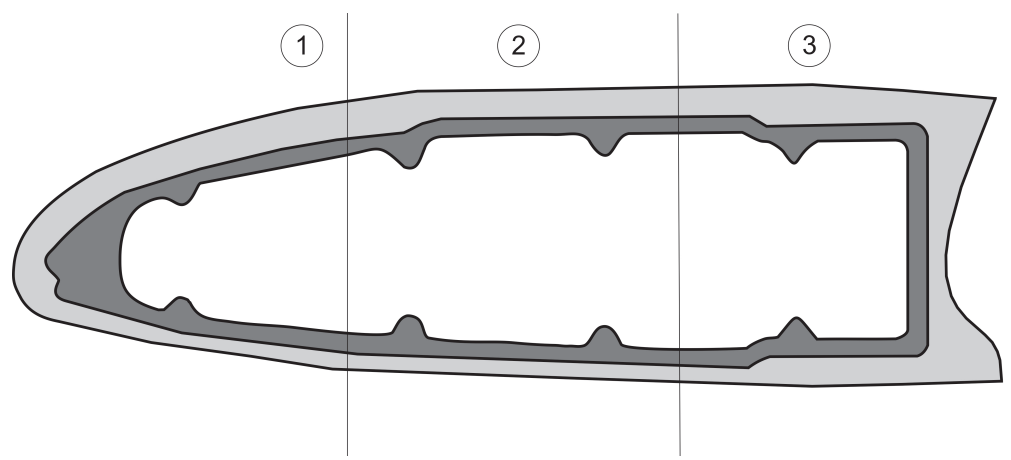

Figure 1. Scheme of the helicopter Mi-2 main rotor blade cross-section focused on D-spar element.

Typically, damage in the main rotor is due to its material ageing $(42 \%)$ or a manufacturing defect (23\%) [41]. The damage types that usually occurred are: blade separation, debonding or crack [41]. The majority of cracks originated from surface defects that occurred during the blade-manufacturing processes (material discontinuity, corrosion pits). On the other hand, in many cases, the origin of fatigue cracks was mechanical scratching of blade surfaces that occurred during incorrect reparation processes. A fatigue crack propagation is not a random process but is strongly related to the loading cycles typicalof a helicopter exploitation process. Mean fatigue cycles number are equal to about $50 \mathrm{~h}$ (100 flights) [41].

\subsection{Investigated Structure}

As mentioned previously, fatigue cracks propagate in the upper or the lower wall of D-spar (a part denoted as (2) - see Figure 1). Therefore, the experimental investigation was performed on a sample of a dimension of $0.3 \mathrm{~m} \times 0.1 \mathrm{~m}$ that had been mechanically extracted from the upper wall of Mi-2 main rotor blade. During the extraction process, attention was paid to not overheat the sample, resulting in changes in its structural properties. The sample thickness was almost stable and its mean value was equal to $0.005 \mathrm{~m}$. The geometry of the sample instrumented with FBG sensors array is presented in Figure 2. 


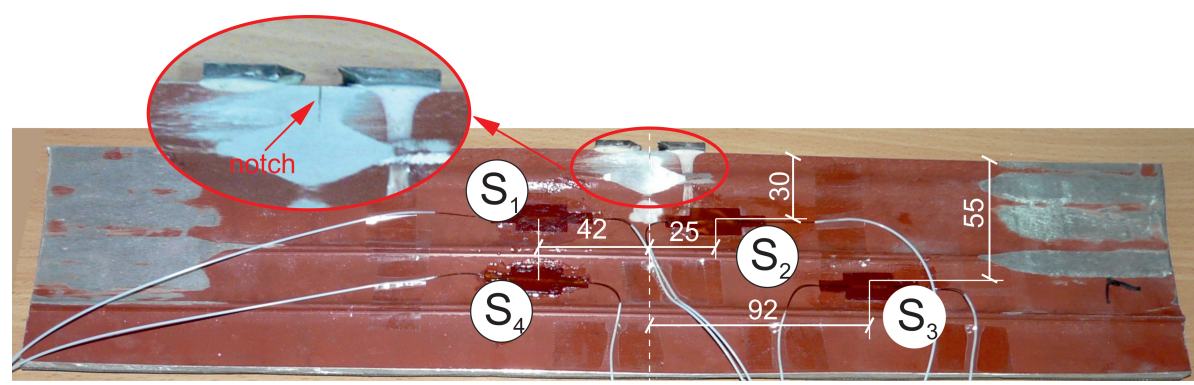

Figure 2. Geometry of the investigated sample with FBG sensors array (FBG are denoted as $S_{1}-S_{4}$ ).

In the middle of the longer side of the sample, a notch was cut to serve as a fatigue crack origin (Figure 3). The notch tip location was chosen based on investigations performed in the Air Force Institute of Technology (AFIT) related to fatigue crack propagation and its origin in the main rotor blade D-spar. Then, the sample was ground on both sides to prepare for clamping in a fatigue machine.

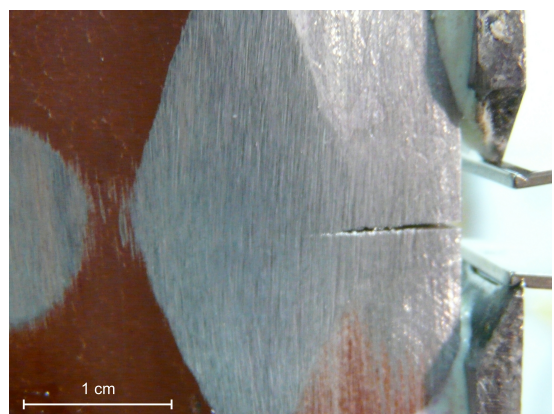

Figure 3. The notch in the sample-the fatigue crack origin.

In order to predict the behaviour of the sample during the fatigue test and to determine the FBG sensors' locations, a finite-element model of the investigated part of the main rotor blade was prepared. The finite-element method (FEM) model with mesh is presented in Figure 4. The model was based on the blade geometry presented in Figure 2 and as a modelling tool, the finite-element package ABAQUS ${ }^{\circledR}$ was used. By using the commercial code strain/stress fields during the crack propagation process, the chosen crack propagation path can be determined.

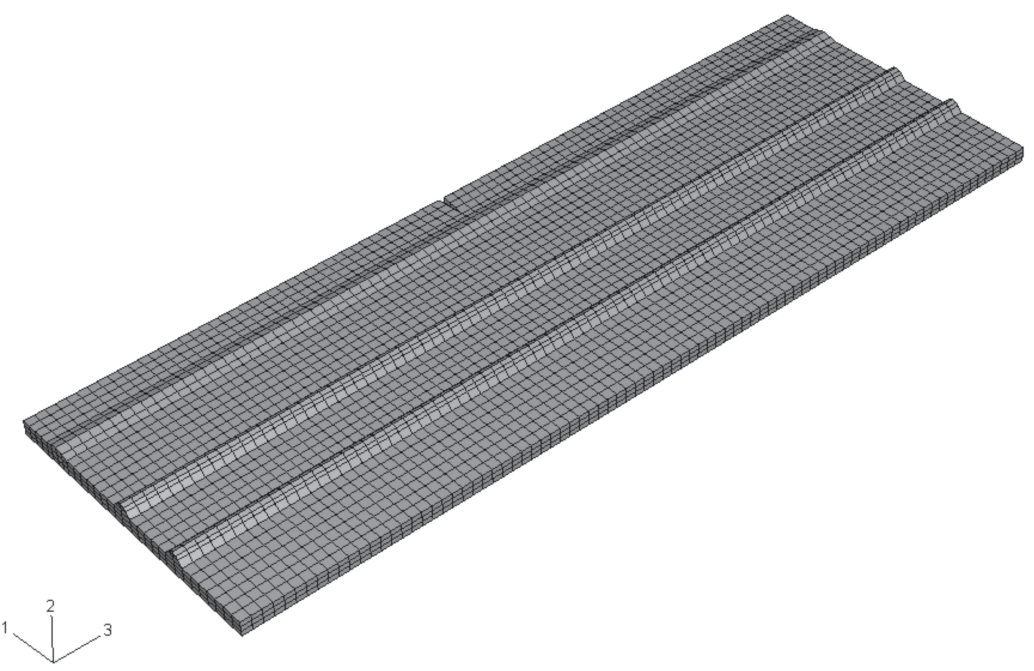

Figure 4. A finite element mesh. 
For the finite-element model of the sample, 8600 elements were used in total, while the number of model degrees of freedom was 133,578. Three-dimensional finite elements (brick of C3D20 type) were employed to model the blade.

\subsection{Fatigue Test Stand}

Based on the numerical investigation results, FBG sensor locations were determined. During the experiment, an FS 6200 Miniature Polyimide Strain Sensors (Fiber Sensing) was used. In this sensor type, a Bragg grating was protected by polyamide coating in the dimension of $40 \mathrm{~mm} \times 12 \mathrm{~mm} \times 0.2 \mathrm{~mm}$. Selected properties of FBG sensors are presented in Table 1.

Table 1. Selected properties of FBG sensor.

\begin{tabular}{ccc}
\hline Property & Value & Unit \\
\hline Wavelength range & $1541-1561$ & $\mathrm{~nm}$ \\
FBG length & 10 & $\mathrm{~mm}$ \\
Strain limit & 4000 & $\mu \varepsilon$ \\
Strain Sensitivity & ca. 1.2 & $\mu \varepsilon$ \\
Accuracy & $+/-2$ & $\mu \varepsilon$ \\
Spectral width (FWHM) & $<0.2$ & $\mathrm{~nm}$ \\
\hline
\end{tabular}

The FBG sensors were placed in locations denoted from $S_{1}$ to $S_{4}$-see Figure 2. Each sensor location along the sample was determined as a distance between the notch axis (dotted line) and the centre of the sensor. Analogically, a similar distance along the sample was determined from the edge (with the notch) of the sample to the centre of each sensor. Three FBG sensors $\left(S_{1}, S_{2}\right.$ and $\left.S_{4}\right)$ were mounted close to the notch tip, while one FBG sensor $\left(S_{3}\right)$ was mounted far from the notch, close to one end of the working area of the sample. Sensors $S_{1}$ and $S_{2}$ were not located symmetrically due to the dimension of the FBG sensors' protective coat. The FBG sensor $S_{4}$ was mounted at the same distance from the notch tip axis as sensor $S_{1}$, but after a stiffener.

During the fatigue test, two sources of the wavelength changes that were measured by the FBG sensors were defined. The first one originated from the fatigue test loading, while the second was related to a fatigue crack propagation process. Sensor $S_{4}$ was used to determine the strain variations related to the load generated by the fatigue machine on an intact part of the element. Sensors $S_{1}, S_{2}$ and $S_{4}$ were used for the determination of fatigue crack propagation.

The instrumented sample was mounted in fatigue machine (MTS 810.23) clamps (Figure 5). Additionally, during the test, extensometer MTS 632.03F-30 was used. The FBG sensor array was equipped using interrogator FS2500 Industrial BraggSCOPE (Fiber Sensing) with a sampling frequency equal to $1 \mathrm{kHz}$. The test was performed at constant temperature, so the temperature compensation was not needed, although the temperature was monitored during the test. 


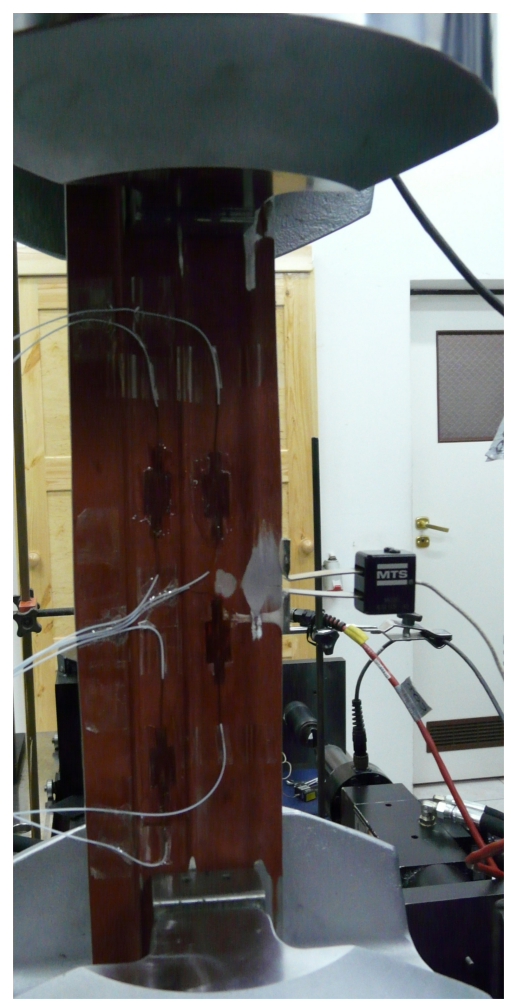

Figure 5. The sample clamped in fatigue machine.

During the test, the sample was loaded cyclically according to the force characteristic presented in Figure 6. The fatigue test consisted of tension cycles from $1 \mathrm{~N}$ to maximum load values under stable frequency $2 \mathrm{~Hz}$. The fatigue test is not strictly based on the Mi-2 main rotor blade loads that occur during its normal exploitation. In contrast with an aircraft wing, a helicopter rotor blade has both its upper and lower surfaces in tension because the centrifugal (tensile) loads exceed the compressive blade-bending loads [42]. The maximum load values were selected for the purpose of moderate fatigue crack propagation velocitymostly achieving stable fatigue crack propagation velocity. The fatigue test parameters were assumed based on the AFIT experience.

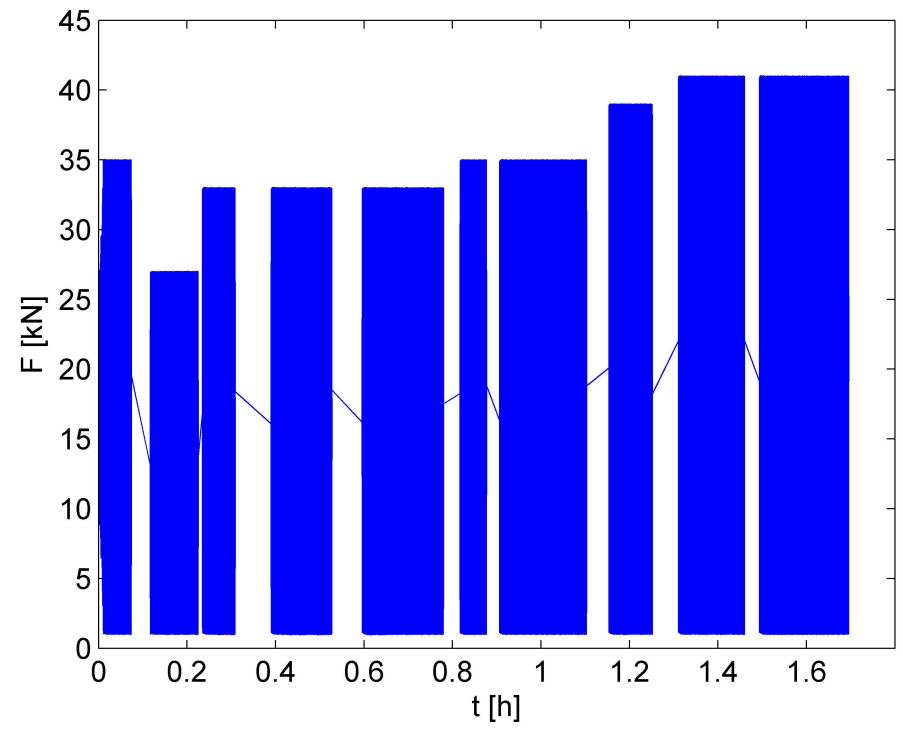

Figure 6. A fatigue force values during the test. 
The test was divided into ten stages, lasting between 300 and 450 s. After every stage, the fatigue machine was stopped and the total length of the crack was measured. Two stages of crack evolution are presented in Figure 7. The length of the crack was measured from the end of the notch tip. The fatigue test was finished when the total length of the fatigue crack exceeded of $25 \mathrm{~mm}$ in length (Figure $7 \mathrm{~b}$ ).

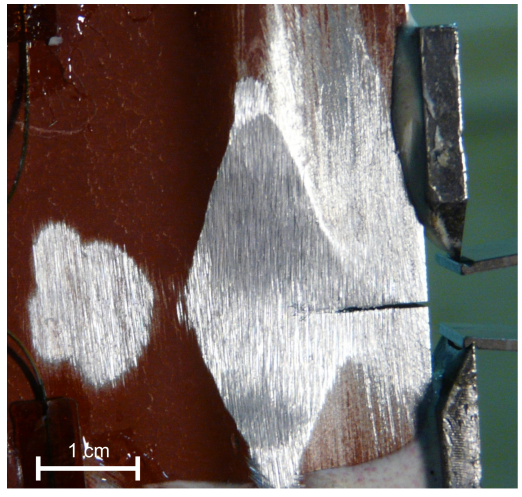

(a)

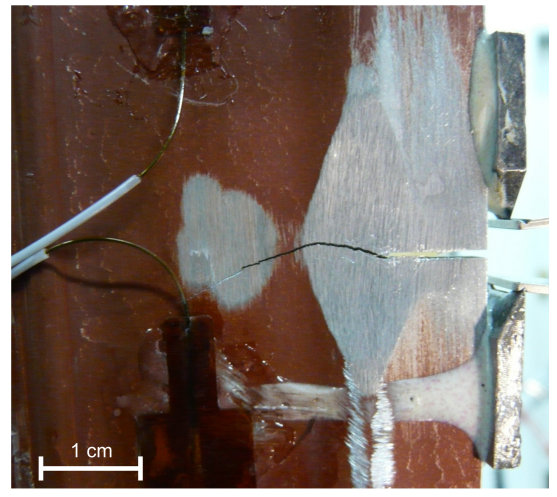

(b)

Figure 7. Photographs of the fatigue crack growth: (a) with a length of $3.6 \mathrm{~mm}$, (b) after the end of the fatigue test.

\section{Results}

\subsection{Strain Analyses}

To determine longitudinal strain distribution over the sample surface, the FEM model was used. This parameter was measured by the FBG sensors in the experimental part of this analysis. The FEM results for two stages are presented: for the fatigue test, beginning with a notch in the sample (Figure 8), and for the end of the fatigue test, when the crack length was equal to $25 \mathrm{~mm}$ (Figure 9).

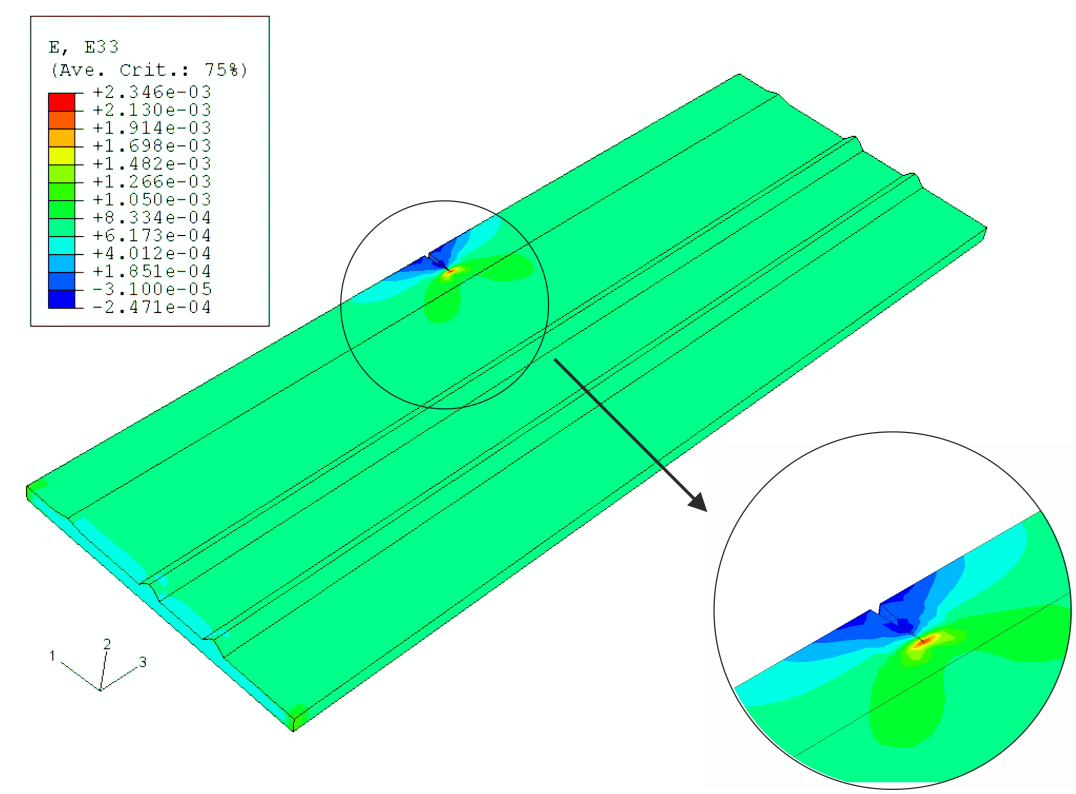

Figure 8. Distribution of the longitudinal strain over a sample surface at the beginning of the fatigue test. 


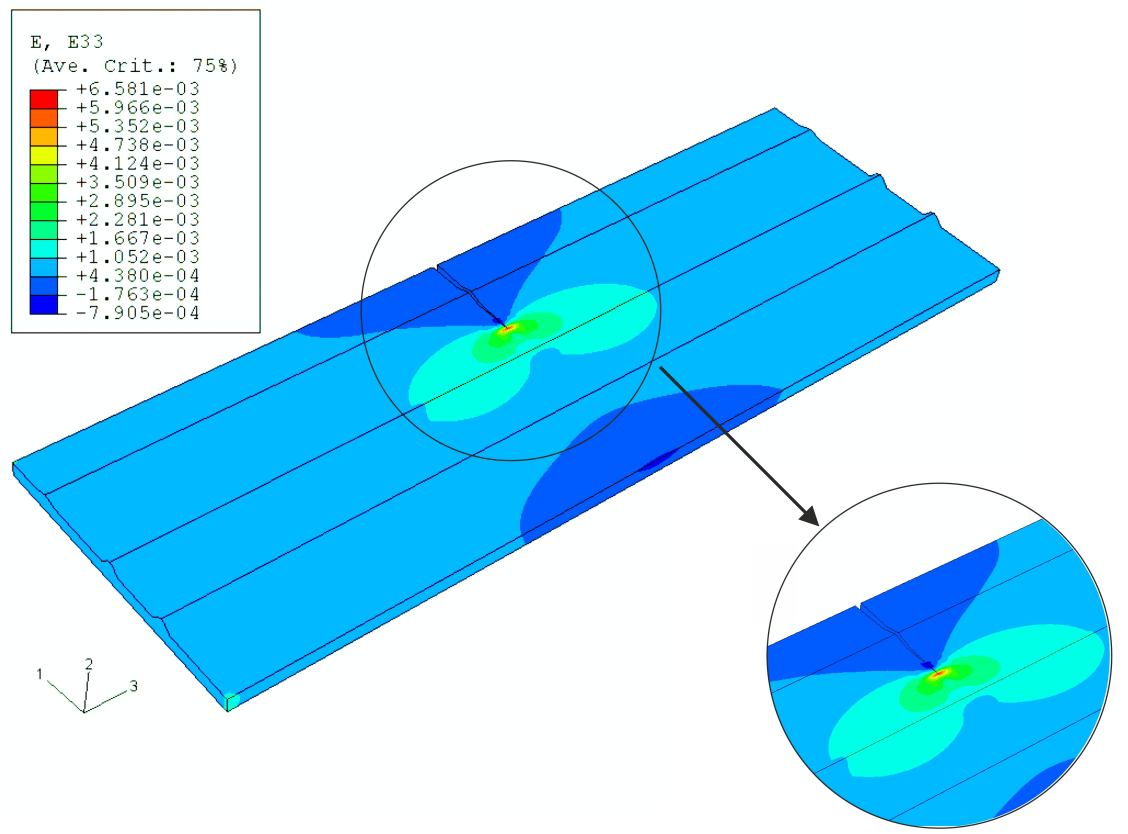

Figure 9. Distribution of the longitudinal strain over a sample surface at the end of the fatigue test.

As visible in Figures 8 and 9, the maximum strain values are in the notch tip. The strain values determined for the FBG sensor locations are collected in Table 2. In the first stage (Figure 8), strain values are similar in all FBG sensors locations, because the FBG sensors $\left(S_{1}\right)$ and $\left(S_{2}\right)$ located closest to the notch were used after the first stiffener. Due to this, the notch tip influence on the strain values was neglected. The situation changes due to fatigue crack evolution. For the last stage (Figure 9), the maximum strain values in all FBG sensors locations were higher than they previously were. The lower values determined for FBG $S_{1}$ and $S_{2}$ are because of the decrease in the sample's effective cross-section.

Table 2. Comparison of strain values, determined experimentally and numerically.

\begin{tabular}{cccc}
\hline \multirow{2}{*}{ Sensor } & \multicolumn{3}{c}{ Strain $\varepsilon \times \mathbf{1 0}^{-\mathbf{4}}[\mathbf{m} / \mathbf{m}]$} \\
\cline { 2 - 4 } & Experiment & Model & Error [\%] \\
\hline & Beginning of the fatigue test \\
\hline S1 & 9.8 & 8.2 & 16.3 \\
S2 & 8.8 & 8.2 & 6.8 \\
S3 & 10.0 & 8.2 & 18.0 \\
S4 & 9.0 & 8.2 & 8.9 \\
\hline \multicolumn{5}{c}{ End of the fatigue test } \\
S1 & 9.0 & 9.0 & 8.2 \\
S2 & 10.0 & 9.0 & 10.0 \\
S3 & 12.5 & 11.0 & 12.0 \\
S4 & 12.8 & 12.0 & 6.3 \\
\hline
\end{tabular}

In Figure 10, the strain values measured by FBG sensors during the fatigue test are presented. The strain values were determined using the following relationship:

$$
\varepsilon_{S i}=\frac{\lambda_{S i}-\lambda_{B S i}}{\lambda_{B S i} F_{G}} \text { for } i=1, \cdots, 4
$$

where $\lambda_{B S i}$ and $\lambda_{S i}$ means Bragg and the measured wavelength, respectively. While $F_{G}$ is a factor gauge that depends on fibre optics' material properties. 

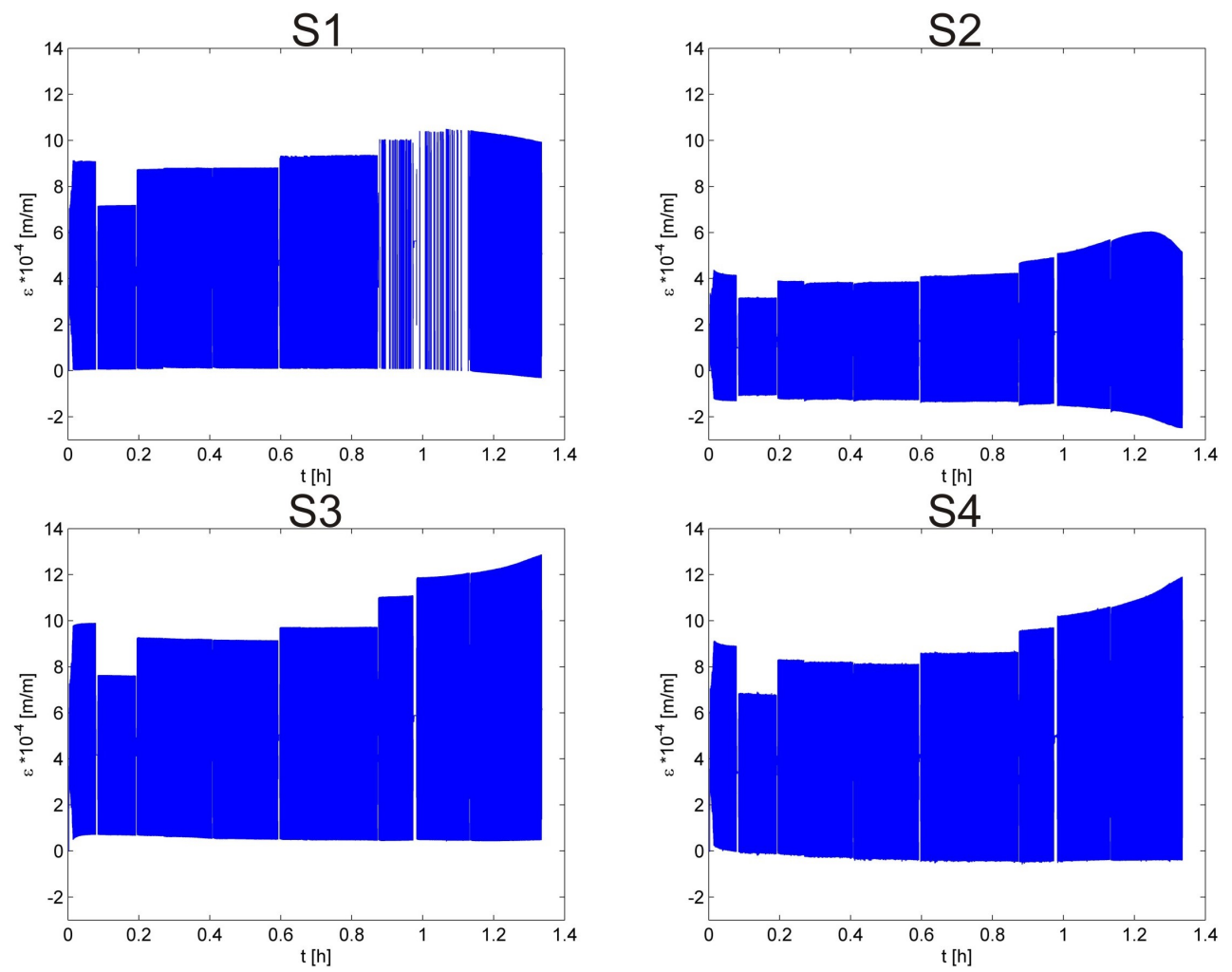

Figure 10. Strain values measured by FBG sensors during fatigue test.

The breaks between the consecutive stages of the test, presented in Figure 10 are minimised for the purpose of presenting the real duration of the fatigue test, which took about $80 \mathrm{~min}$. The strain curves remained the shape of the load signal registered by the fatigue test machine-see Figure 6. A small exception is presented in the graph determined for sensor $S_{2}$ (Figure 10). The sensor was likely prestrained during the gluing process, so it also showed negative strain values (suggesting the compression behaviour of the sample). Additionally, the strain amplitudes are about half the value of those registered for the other FBG sensors. It is worth noting that the crack propagation process is visible on all strain curves, but only during the two last stages of the fatigue test when the crack was no shorter than $20 \mathrm{~mm}$. For two sensors, denoted as $S_{1}$ and $S_{2}$ (located before the stiffener), the strain values were decreasing, showing a local small compression. For the other two sensors $\left(S_{3}\right.$ and $S_{4}$ ), mounted after the first stiffener, the registered strain values increased at the end of the fatigue test. The differences are due to the fatigue crack propagation process and the different behaviour of the material when close to the crack tip, as well asa the change in the dimension of the effective cross-section of the sample.

The comparison of the maximal longitudinal strain values, determined experimentally using FBG sensors and achieved from the FEM calculation for the FBG sensor locations, is presented in Table 2. For each case, the percentage error was determined according to the following equation:

$$
\varepsilon_{S i}(t)=\left|\frac{\varepsilon_{S i}^{m}(t)-\varepsilon_{S i}^{a}(t)}{\varepsilon_{S i}^{m}(t)}\right| 100 \% \text { for } i=1, \cdots, 4
$$

where indexes $m$ and $a$ refer to the strain values measured and calculated using FEM, respectively. The average percentage error for all cases was $10.8 \%$. It can clearly be seen that the obtained results of experimental measurements (Figure 10) are in good agreement with the results of FEM calculations (Figures 8 and 9). 


\subsection{Spectrogram Analyse}

For the purpose of vibration analyses, the strain signals (measured by FBG sensors) were converted into the time-frequency domain using the Short Time Fourier Transformation. This is based on a time window moving along the time domain in which the Fast Fourier Transformation is conducted. The spectrogram is obtained, which depicts the signal power as a function of time and frequency. Thanks to its nature, the simultaneous analysis of time and frequency can be conducted. The transformation can be described by

$$
S_{x(t, f)}=\int_{-\infty}^{\infty} x(t) w(t-\tau) e^{-j 2 \pi f t} d t
$$

where: $x(t)$-time domain signal, $w(t-\tau)$ - time window, $f$-frequency, $j$-imaginary unit. During the experimental analyses, the Hamming window was used, with a length of 200 points and a $50 \%$ overlap. The product of the window width in the time domain $\Delta t$ and in the frequency domain $\Delta f$ is a constant value for a given window. Therefore, improving the resolution in the time domain results in a deterioration of resolution in the frequency domain. As the analysed crack propagation process was mostly time-dependent, a narrow window width was chosen in the time domain. This was equal to 200 measurement points.

The spectrogram is defined by

$$
\operatorname{Spec}=\left|S_{x(t, f)}\right|^{2} .
$$

It represents the signal in a 3D space and allows for an investigation of of the time instants at which each frequency component is present.

The spectrogram analysis was performed for all stages of the fatigue test. In Figures 11-14, the processed signals for few chosen stages of the fatigue test are presented. For each case, the results are presented in the form of four spectrograms according to the number of FBG sensors. The spectrograms are denoted as $S_{1}$ to $S_{4}$ according to the FBG sensors' numbers $\left(S_{1}\right.$ to $\left.S_{4}\right)$.

The spectrograms from the first stage of the experiment are presented in Figure 11. For FBG sensor $S_{1}$, only a part of the data was registered. This was a result of bending the fibre optic connecting the array of FBG sensors. A response observed during the measurements in the range of $50 \mathrm{~Hz}$ originated from the fatigue test loading. This phenomenon is visible on all spectrograms for all FBG sensors, and is stable for all sensors during the whole fatigue test. There is also an additional frequency $(222 \mathrm{~Hz})$ that is excited during all stages of the fatigue test. It is observed only on spectrograms determined for sensors $S_{2}$ and $S_{4}$.
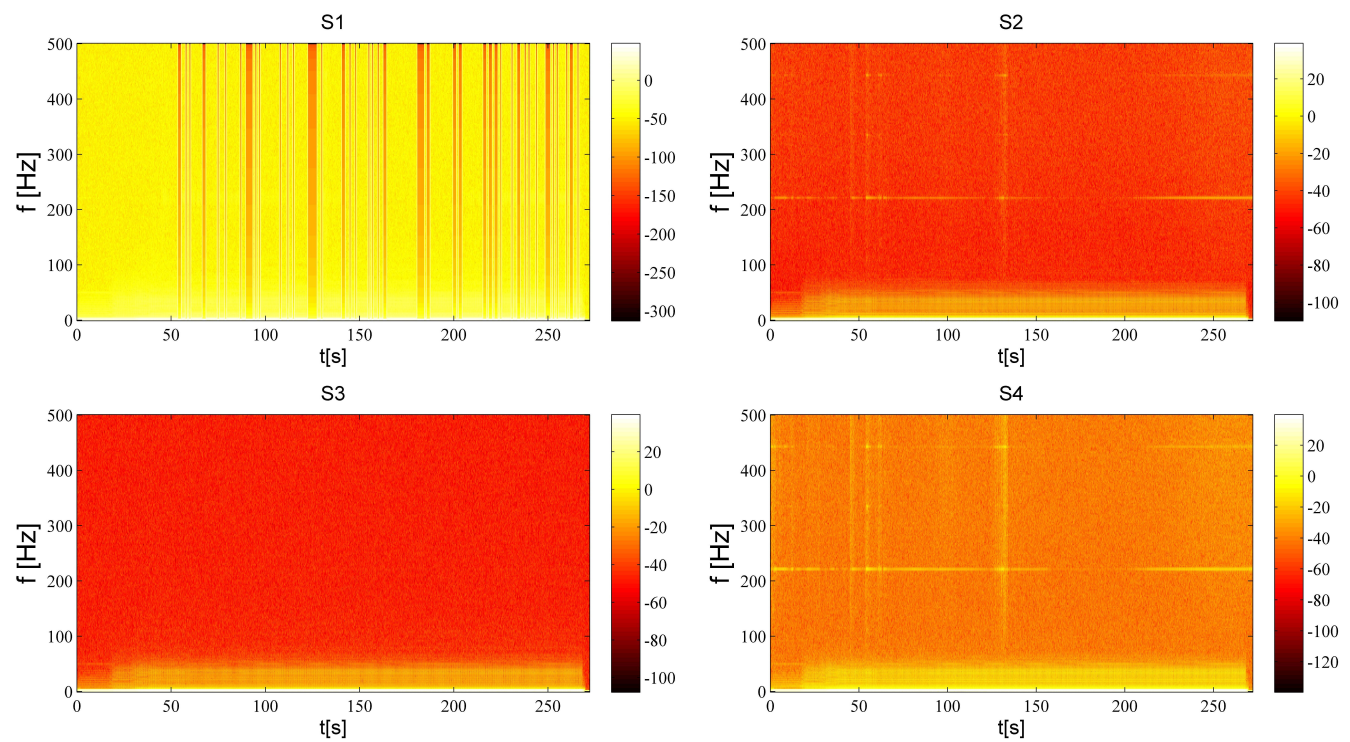

Figure 11. Spectrograms from the first stage of the fatigue test. 
In the spectrograms performed for FBG sensors $S_{1}, S_{2}$ and $S_{4}$, located close to the notch tip, the system response in a wide range of frequencies can be observed. In the Figure 11, this can be determined about $50 \mathrm{~s}$ and $120 \mathrm{~s}$ from the beginning of the fatigue test. On the spectrogram made for data registered by sensor $S_{3}$, which was mounted close to the clamp of the fatigue machine, such a phenomenon was not observed.

This phenomenon can be combined with fatigue crack propagation observations using a magnifying glass. The crack occurrence after $120 \mathrm{~s}$ of the test was long enough to be visible using the magnifying glass. After $300 \mathrm{~s}$ of the test, the fatigue machine was stopped. Then, the length of the fatigue crack was measured. The total length of the crack (measured from the end of the notch tip) was equal to $2.3 \mathrm{~mm}$.
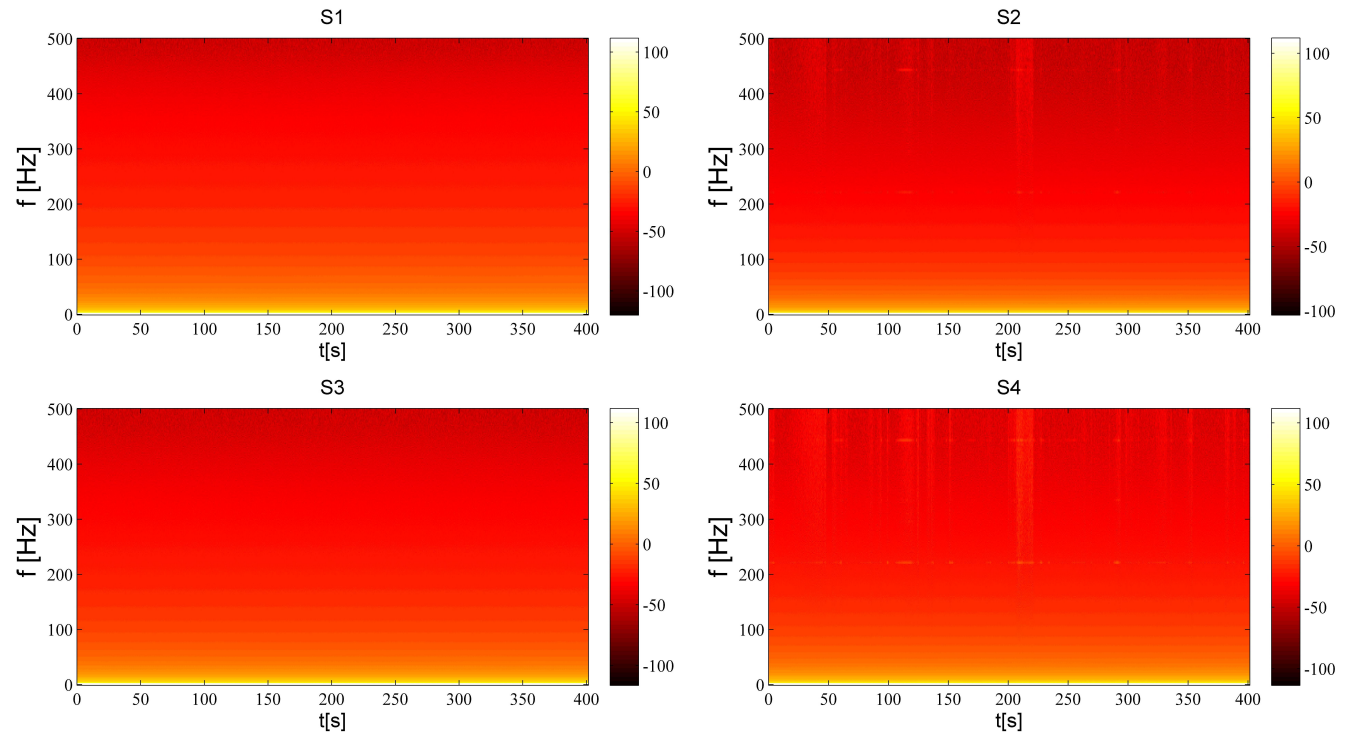

Figure 12. Spectrograms from the second stage of the fatigue test.

Spectrograms for the second stage of the fatigue test are presented in the Figure 12. The maximum loading value, in this case, was smaller than in the previous stage. It was changed to reduce the crack propagation velocity. During this stage, the crack was not propagating, so the length of the crack after this stage was the same as after the previous one. The spectrograms for all FBG sensors were similar, showing only the loading from the fatigue machine. The phenomena referred to as the crack evolution were not observed during this stage.
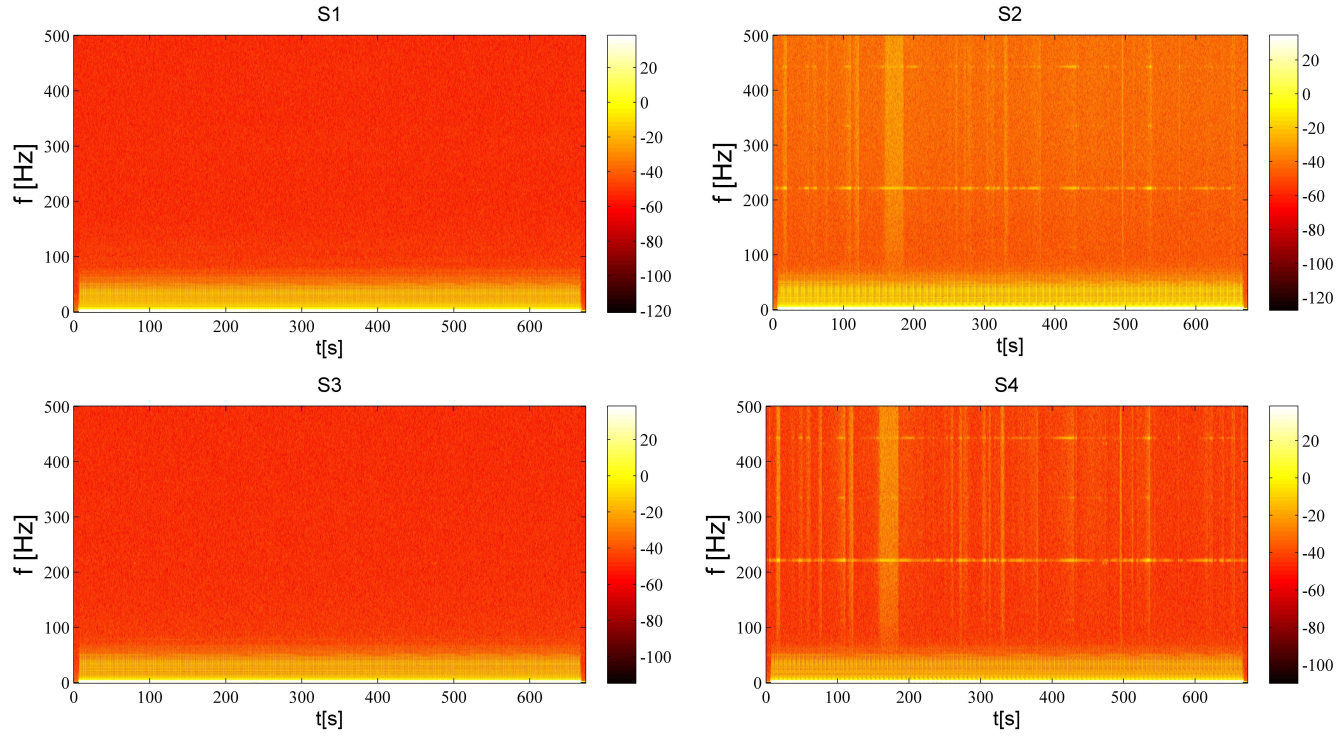

Figure 13. Spectrograms from the fifth stage of the fatigue test. 
Spectrograms for FBG sensors for the fifth stage of the fatigue test are presented in Figure 13. The phenomenon of system responses in a wide range of frequencies is visible on spectrograms for sensors $S_{2}$ and $S_{4}$, especially in a range between $180 \mathrm{~s}$ and $200 \mathrm{~s}$ from the beginning of the stage. The total length of the crack after the stage was equal to $3.6 \mathrm{~mm}$ (Figure 7a). In this case, the phenomenon can also be connected with the crack evolution.
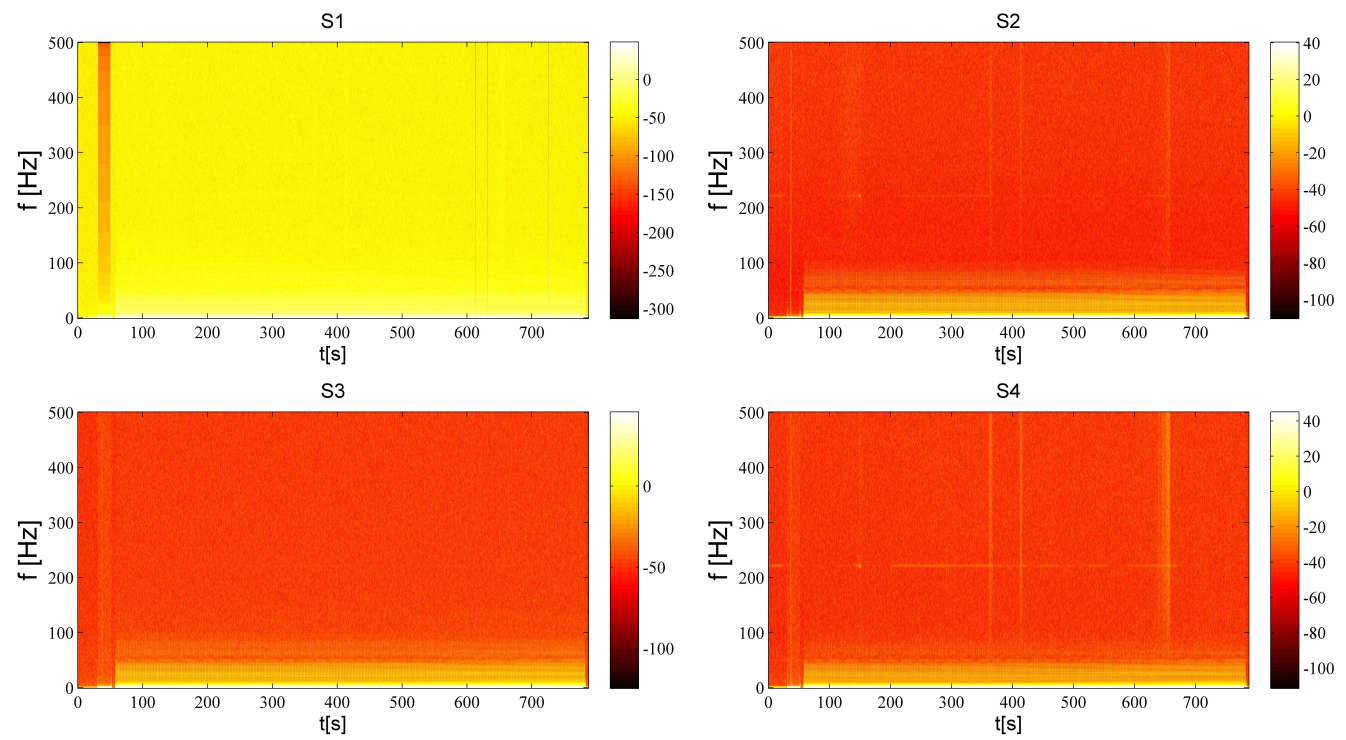

Figure 14. Spectrograms from the tenth stage of the fatigue test.

In Figure 14 spectrograms for the last stage of the fatigue test are presented. The phenomenon of the response of the system in a wide range of frequencies is visible on the spectrograms for sensors $S_{2}$ and $S_{4}$, about $400 \mathrm{~s}$ and $650 \mathrm{~s}$ from the beginning of the stage. The total length of the crack after the end of the fatigue test was equal to $27 \mathrm{~mm}$, and is presented in Figure $7 \mathrm{~b}$.

\subsection{Strain Trends}

The strain curves determined experimentally using the FBG sensors (Figure 10) contain an influence originating from both fatigue loading and the blade material degradation process. To obtain strain values trends in the blade, the measured strain signals were filtered and all frequencies higher than $1.5 \mathrm{~Hz}$ were removed, as they were related to the fatigue test-loading characteristics.

The results for the four chosen stages are presented in Figures 15-18. They present strain trends, around which the strain oscillates during the fatigue test. For the purpose of better visibility, similar strain ranges were chosen for the sensors. The first range was equal to $2.5 \times 10^{-4}$ for the first (Figure 15) stage and for sensor $S_{1}$ in the tenth (Figure 18) stage, where the strain changes were the highest. The second range equal to $0.4 \times 10^{-4}$ was applied for the second (Figure 16) and the fifth (Figure 17) stages, as well as the rest of the sensors (except sensor $S_{1}$ ) in the tenth (Figure 18) stage, where the strain changes were the smallest. This allows for the presention of changes in the strain profiles, which were related to the crack propagation process.

The strain trends received for the first stage of the fatigue test are presented in Figure 15. The strain variations observed for sensor $S_{1}$ are due to the previously explained bending of the fibre. Only the influence of the beginning and the end of the stage are visible. The strain level is almost stable for all sensors. 

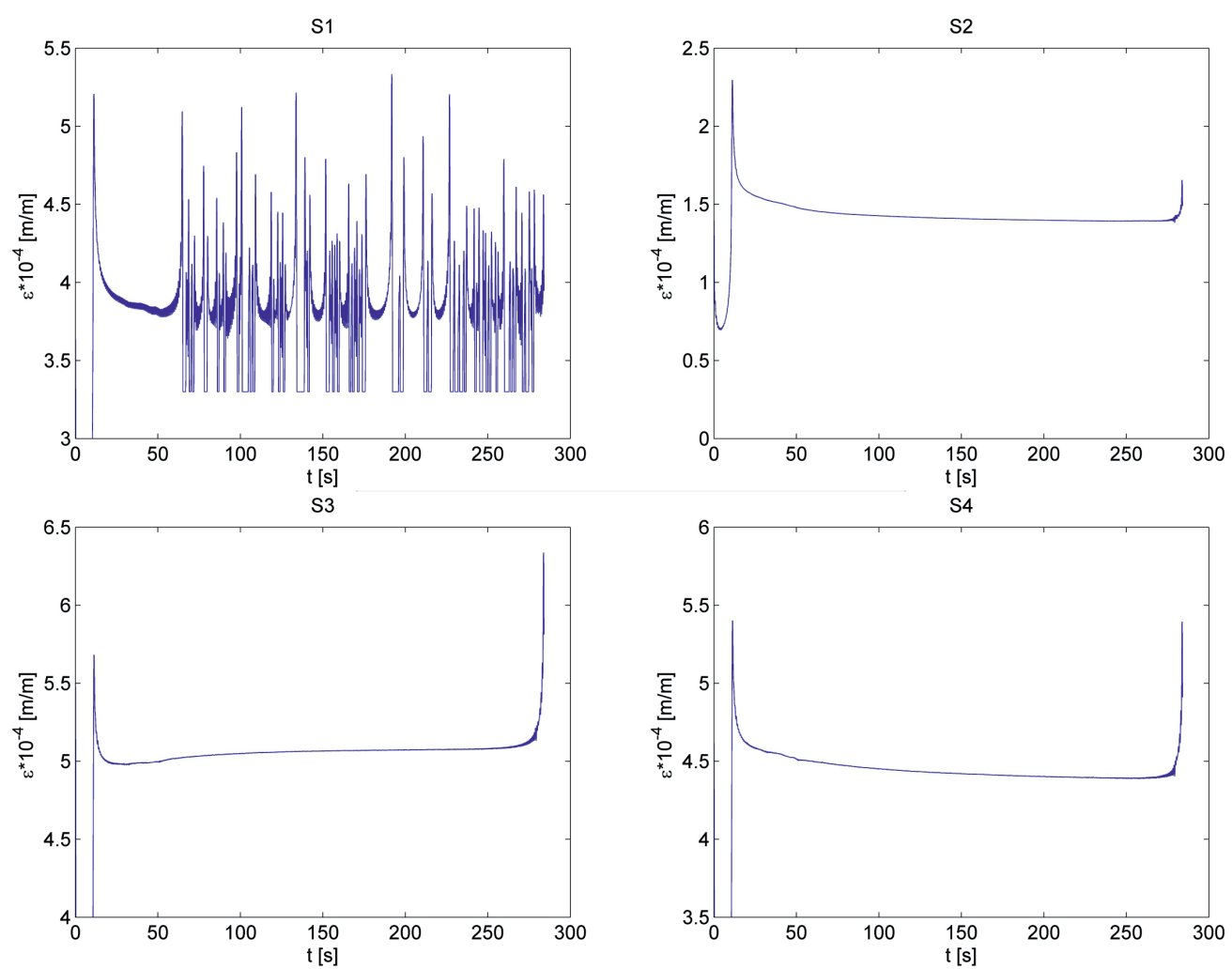

Figure 15. Strain trends for the first stage of the fatigue test.

The strain trends received for the second stage of the fatigue test are presented in Figure 16. As in the previous stage, there is no indication of the fatigue crack propagation. Strain changes close to $20 \mathrm{~s}$ from the beginning of the stage are related to an unexpected change in the force level.
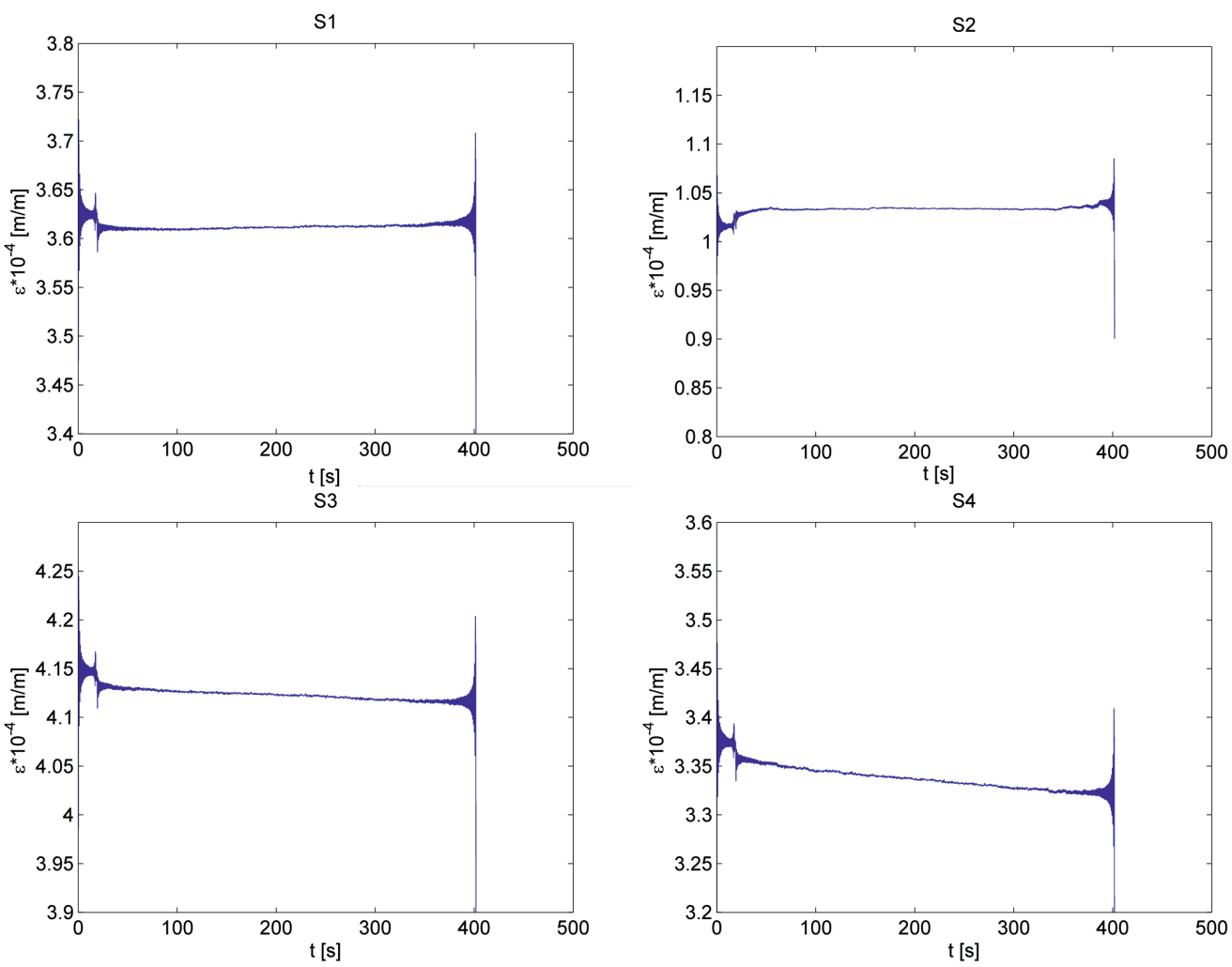

Figure 16. Strain trends for the second stage of the fatigue test. 
The strain trends received for the fifth stage of the fatigue test are presented in Figure 17. About $200 \mathrm{~s}$ from the beginning of the test, a small peak $\left(2 \times 10^{-6} \mathrm{~m} / \mathrm{m}\right)$ is observed for the FBG sensor $S_{2}$. It is worth notin that the change level is close to the sensitivity of the used interrogator, which is equal to $1 \times 10^{-6} \mathrm{~m} / \mathrm{m}$. The peak is observed at the same time as the response of the investigated sample in a wide range of frequencies in the spectrogram analysis (Figure 13).
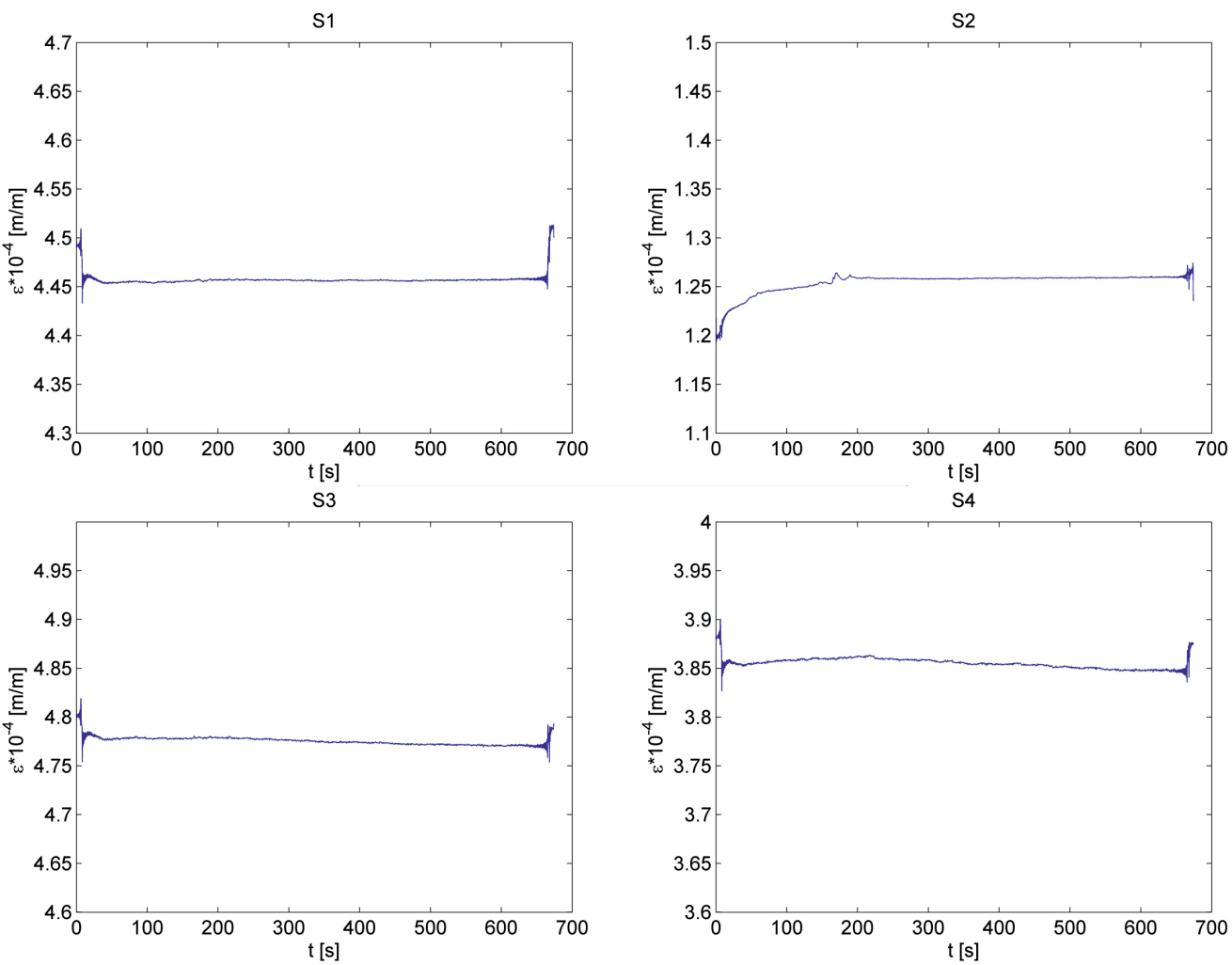

Figure 17. Strain trends for the fifth stage of the fatigue test.

The strain trends for the tenth stage of the fatigue test are presented in Figure 18. A strong decrease in the strain is observed for the FBG sensor $S_{2}$, while, at the same time, a strong increase in the strain values is registered by sensor $S_{4}$. In the graph for the FBG sensor $S_{2}$, two peaks are observed at $400 \mathrm{~s}$ and $650 \mathrm{~s}$ from the beginning of the stage. They are observed at the same time as the response of the investigated sample, in a wide range of frequencies, in the spectrogram analysis (Figure 14). The peak amplitude is similar, as it was observed during the fifth stage of the test. 

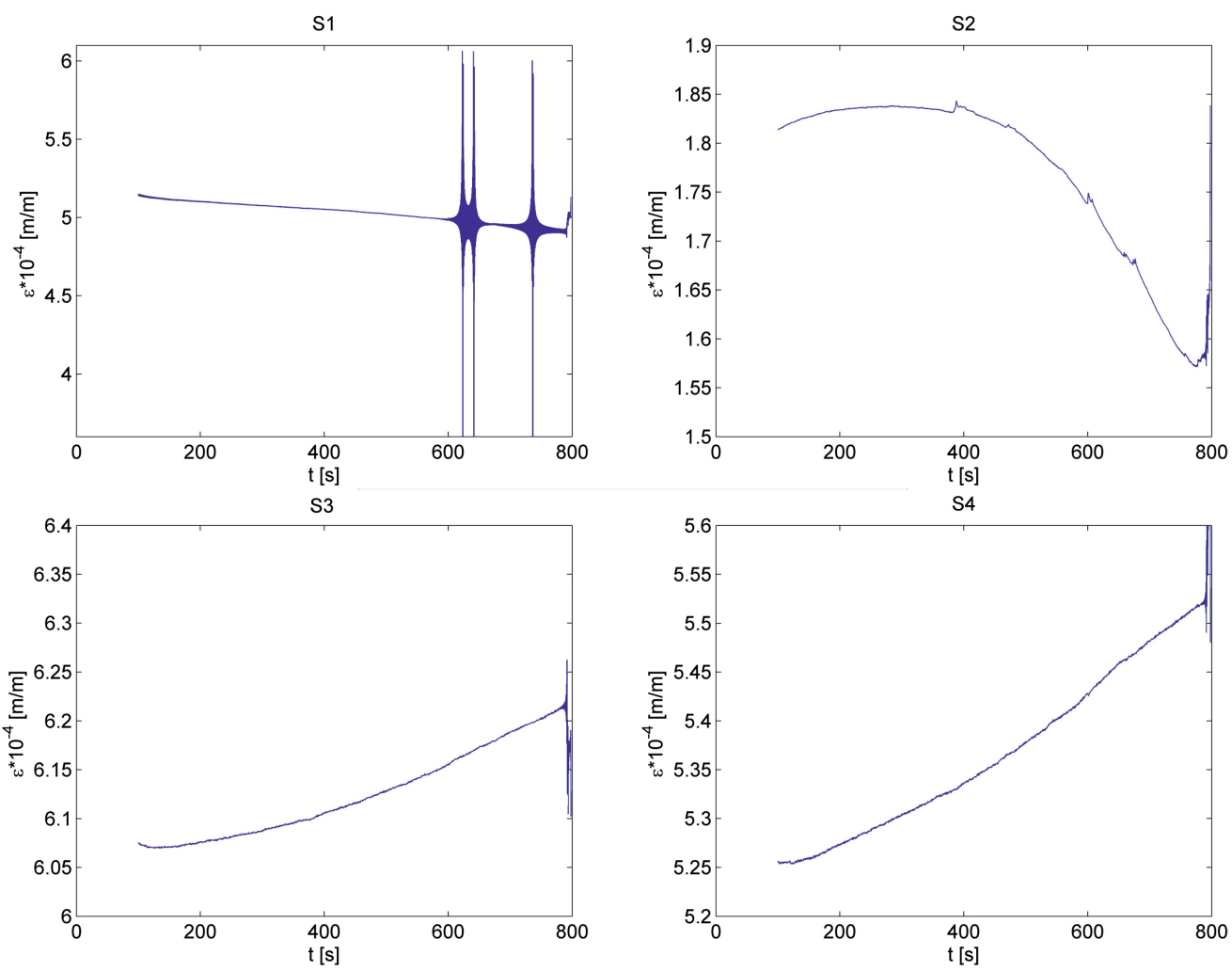

Figure 18. Strain trends for the tenth stage of the fatigue test.

\section{Results and Discussion}

In this paragraph, some important FBG sensor measurement results of a fatigue test are presented and discussed.

The frequencies $(222 \mathrm{~Hz}$ and $448 \mathrm{~Hz}$ ) observed during the spectrogram analysis are probably related to the first three natural frequencies (bending form) of the analysed sample. According to the numerical simulation results, they are equal to $233 \mathrm{~Hz}, 753 \mathrm{~Hz}$ and $1565 \mathrm{~Hz}$. As the measurement frequency of the interrogator was equal to $1000 \mathrm{~Hz}$, the two natural frequencies were too high to satisfy the Nyquist criterion and the aliasing effect occurred. Therefore, the frequency of $222 \mathrm{~Hz}$, observed experimentally, is related to the first mode and the second mode (aliasing). While the measured frequency $448 \mathrm{~Hz}$ is related to the third mode (aliasing). The observability of the natural frequencies in spectrograms originating from different sensors is related to their location on the sample and the shapes of the vibration mode. Therefore, they are only visible on the spectrograms og two sensors $\left(S_{2}\right.$ and $\left.S_{4}\right)$. For the other sensors, the strain associated with the natural frequency modes was too small to be noticed by the sensors. The limitations of the application of FBG sensors (strain-measuring devices) for natural frequency determination was described in [7].

The spectrograms presented in Figures 11-14 showed that a crack propagation influence is not visible on any of the spectrograms determined for sensor $S_{3}$. As mentioned previously, sensor $S_{3}$ was close to the machine clamps to determine frequency responses that originated from the fatigue test (Figure 2). Therefore, it can be assumed that sensor $S_{3}$ is only influenced by the fatigue test loading spectrum. The phenomena related to the fatigue test loading are visible in all spectrograms for all FBG sensors. Therefore, it can be assumed that the influence of the fatigue test is similar for all FBG sensors mounted on the sample.

Based on those assumptions, the spectrograms from FBG sensors $S_{1}, S_{2}$ and $S_{4}$ were processed for the purpose of better visibility of the crack propagation influence. For each stage, the differences between spectrograms for sensor $S_{3}$ and other sensors were determined. As, during the fatigue test, a lack of transmission data from sensor $S_{1}$ occurred, 
the results presented for the sensor contain high-frequency amplitudes that are not related to the fatigue test.

As mentioned previously, the influence of the fatigue test on the system responses occurred up to a frequency of $50 \mathrm{~Hz}$. Due to this, in Figures 19-22, the frequency range was narrowed to from $100 \mathrm{~Hz}$ to $500 \mathrm{~Hz}$.

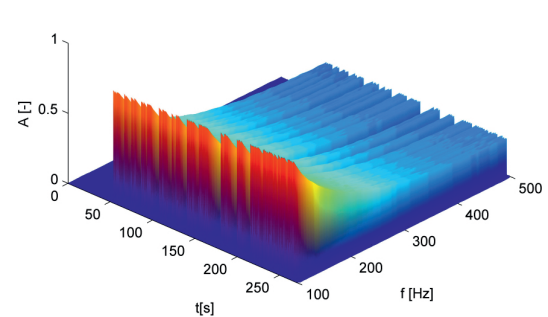

(a)

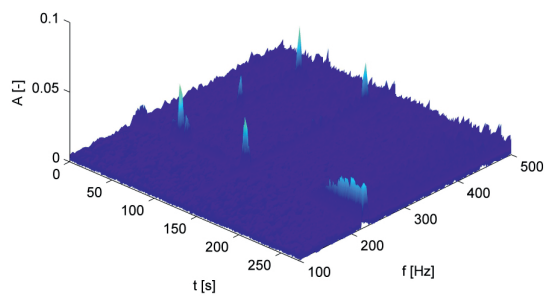

(b)

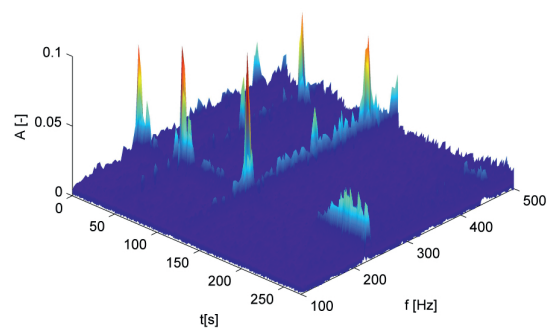

(c)

Figure 19. Differences for spectrograms, for the first stage of the fatigue test, for sensor: (a) $S_{1}$, (b) $S_{2}$, (c) $S_{4}$.

Figure 19 presents the differences between spectrograms determined for the first stage of the fatigue test. The phenomenon of the system response in a wide range of frequencies observed in Figure 11 in spectrograms for FBG sensors was $S_{2}$ and $S_{4}$ about $50 \mathrm{~s}$ and $120 \mathrm{~s}$, and is also visible in Figure 19. There are additional high peaks for a frequency equal to $222 \mathrm{~Hz}$. Such a frequency is usually excited in the fatigue test stage. The maximum amplitude values are higher for sensor differences of $S_{4}$ than they are for sensor differences of $S_{2}$, because sensor $S_{4}$ was located closer to the crack tip than sensor $S_{2}$.

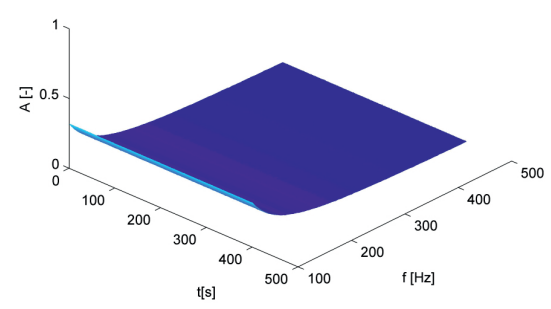

(a)

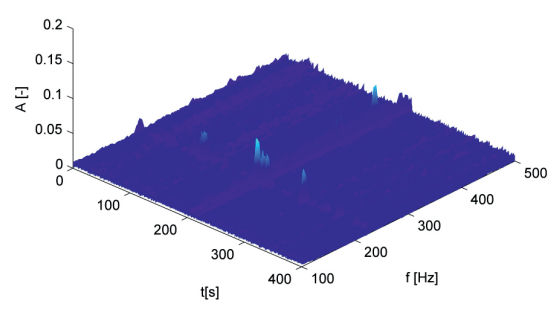

(b)

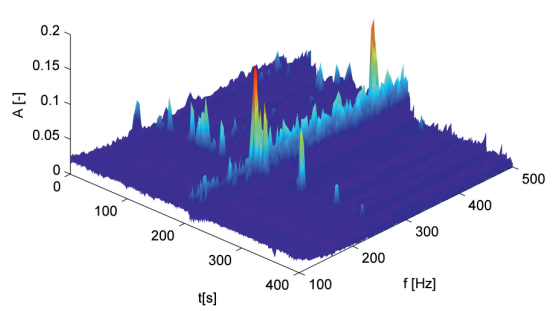

(c)

Figure 20. Differences for spectrograms, for the second stage of the fatigue test, for sensor: (a) $S_{1}$, (b) $S_{2}$, (c) $S_{4}$.

The differences in spectrograms for the second stage of the fatigue test are presented in Figure 20. The crack propagation process was not observed using the magnifying glass or during the first spectrogram analysis (Figure 12). The response of the spectrum in a wide range of frequencies is visible in spectrogram differences about $210 \mathrm{~s}$ from the beginning of the stage of the fatigue test for sensors $S_{2}$ and $S_{4}$. The amplitude values of the phenomenon were to small to observe during the previous analysis. Therefore, the crack evolution also occurred during this stage, but the crack propagation velocity was too small to noticably elongate the fatigue crack using the magnifying glass, even after the end of the stage. The frequency equal to $222 \mathrm{~Hz}$ is also excited during the fatigue test stage.

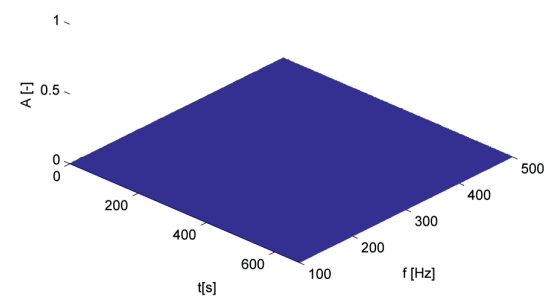

(a)

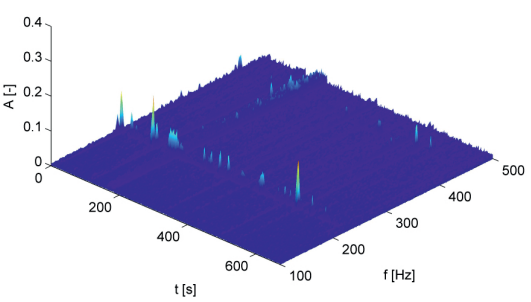

(b)

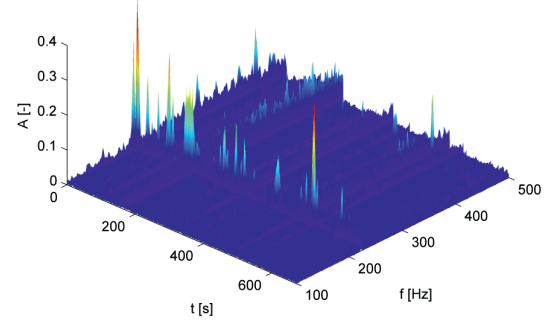

(c)

Figure 21. Differences for spectrograms, for the fifth stage of the fatigue test, for sensor: (a) $S_{1}$, (b) $S_{2}$, (c) $S_{4}$. 
The differences in spectrograms for FBG sensors for the fifth stage of the fatigue test are presented in Figure 21. The phenomenon of the system responses in a wide range of frequencies is visible on both graphs (for sensors $S_{2}$ and $S_{4}$ ) in a range between $180 \mathrm{~s}$ and $200 \mathrm{~s}$, as well as about $350 \mathrm{~s}$ and $480 \mathrm{~s}$ from the beginning of the stage. The first range is easily determined for the spectrogram analyses-see Figure 13. The frequency $222 \mathrm{~Hz}$, excited during the fatigue test, has a high amplitude over the whole stage.

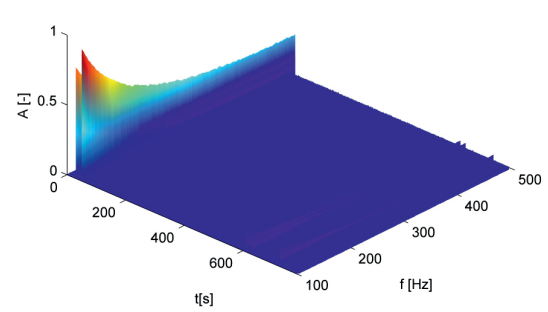

(a)

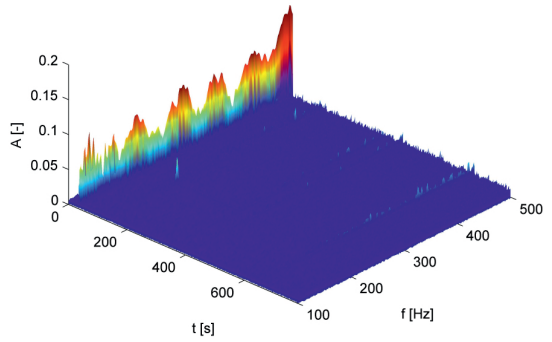

(b)

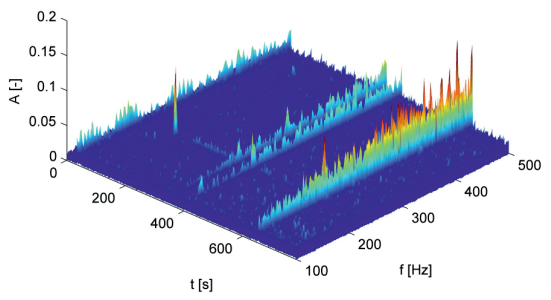

(c)

Figure 22. Differences for spectrograms, for the tenth stage of the fatigue test, for sensor: (a) $S_{1}$, (b) $S_{2}$, (c) $S_{4}$.

In Figure 22 differences of spectrograms for the last stage of the fatigue test are presented. The phenomenon of the system response in a wide range of frequencies related to crack propagation is visible in the differences for sensor $S_{4}$ ). The phenomenon occurs in a range from $380 \mathrm{~s}$ to $400 \mathrm{~s}$ as well as about $650 \mathrm{~s}$ from the beginning of the tenth stage of the fatigue test. The second range can be also easily determined for the spectrogram analyses—see Figure 14.

The differences among the spectrograms presented in Figures 19-22 indicate two types of areas with high amplitudes. The first is related to the natural frequencies of the sample (especially the first mode) and are observed for stable frequencies. While the second is related to the fatigue crack propagation and is observed for stable time values. For the purpose of determining the crack propagation process and distinguishing the amplitude changes related to the crack from those linked with the natural frequencies, the following calculations were proposed. Based on the observations presented above, two indicators $\left(F_{S k}\right.$ and $C_{S k}$ ) were determined. They are related to frequency and crack influences on the amplitude values, respectively. The indexes are described by the following relationships

$$
\begin{gathered}
F_{S k}(t)=\sum_{i=1}^{n} A_{i, j}, \text { where } j=\text { const, } k=2,4 \\
C_{S k}(f)=\sum_{j=1}^{m} A_{i, j}, \text { where } i=\text { const }, k=2,4
\end{gathered}
$$

where $A_{i, j}$ is an element of matrix $A$ that contains all differences of the amplitudes for the chosen sensor $S_{2}$ or $S_{4}$. The matrix dimension is $n \times m$. Indexes $i$ and $j$ are related to time and frequency, respectively.

A comparison of indexes $F_{S k}$ and $C_{S k}$ is presented in Figure 23. The base values $(B)$ were determined as mean amplitude values for frequencies lower than $200 \mathrm{~Hz}$. Such values are similar for both sensors. It can be seen that both indicator $\left(F_{S k}, C_{S k}\right)$ values are higher than the base $(B)$, except for the tenth stage, where the natural frequency mode is almost invisible for both sensors. For the remaining stages, the $F_{S k}$ is much higher than $C_{S k}$. However, it is easy to distinguish between both indicators. It is worth mentioning that the $C_{S k}$ indicators increase or stabilise with time (stages) for both sensors. It can therefore be concluded that the crack propagates. This agrees with the observations performed during the fatigue test. 


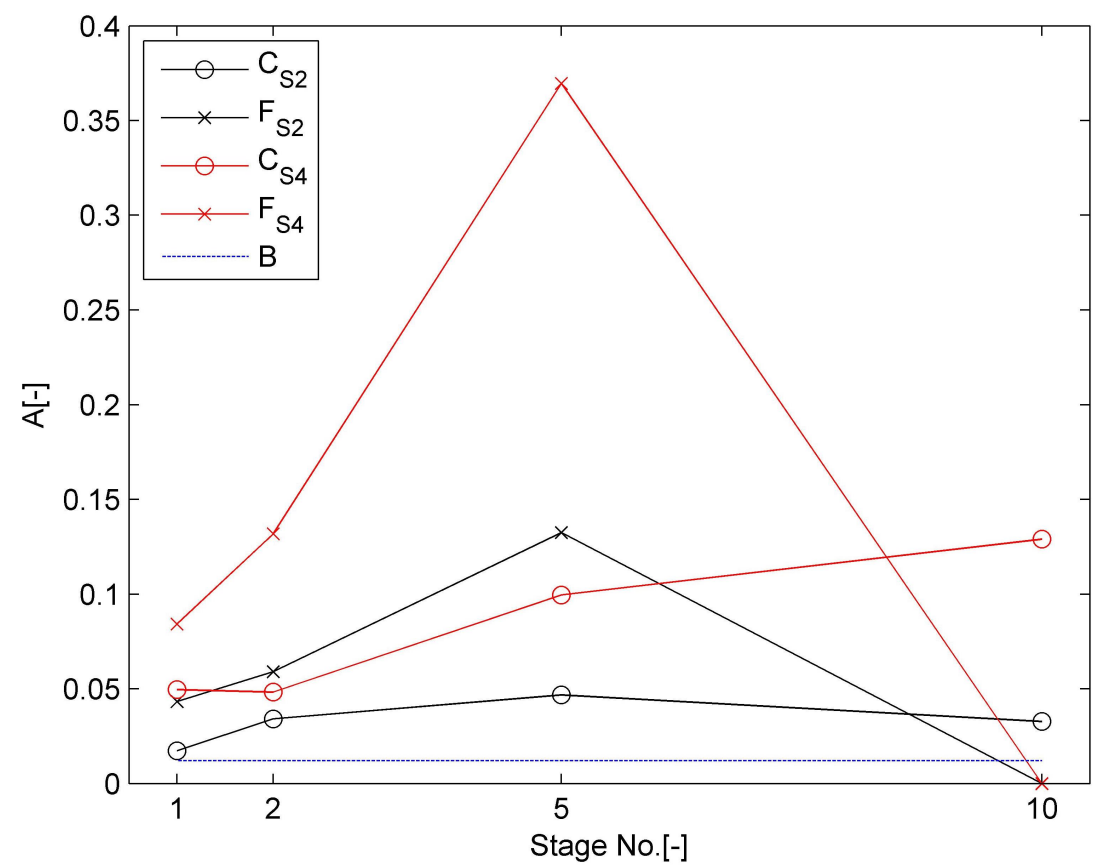

Figure 23. Comparison of differences in amplitudes for spectrograms for sensors $S_{2}$ and $S_{4}$ : C-crack, $F$-natural frequencies, $B$ - base.

\section{Conclusions}

In this paper, the application of FBG sensors in fatigue crack propagation monitoring is presented and discussed. The investigations were performed on a metal sample extracted from the main rotor blade of the Mi-2 helicopter. During the fatigue test, FBG sensors were applied for strain value determination and strain-based vibration analyses. The strain values (at the beginning and end of the test) were compared to the ones determined using the FEM method with good agreement. The average percentage error was equal to $10.8 \%$. Additionally, it was observed that the fatigue-loading profile shape is mapped by all FBG sensors.

The strain trends were determined for all sensors. It was concluded that strain measurements are almost insensitive to the crack propagation process. The crack evolution was observed in only a few cases when the crack propagation resulted in a sudden local change in the strain distribution. It is worth noting that the crack propagation process is visible on all strain curves for the crack longer than $20 \mathrm{~mm}$. Therefore, the method based on the strain values cannot be applied for the determination of small crack propagation.

Therefore, the vibration analyses were performed, and the results were presented in the form of spectrograms and the differences between them for chosen stages of the test. The differences between the achieved results were related to the sensor location on the sample. The higher sensitivity of the vibration phenomena was observed for sensors $S_{2}$ and $S_{4}$, located closer to the crack and its propagation path. However, sensor $S_{3}$, mounted closer to the fatigue machine clamps, was almost insensitive to the vibration. On the spectrograms, the three first natural frequencies of the sample were observed. The bending modes were determined numerically using FEM and the numerical analyses explained the high visibility of frequency $222 \mathrm{~Hz}$ (the first mode) and $448 \mathrm{~Hz}$ (frequency related to the aliasing related to the third mode). On the spectrograms, a spectrum response phenomenon was observed in a wide range of frequencies. During the crack propagation process, mechanical waves are excited, which propagate through the material of the sample [43]. The phenomenon was observed during the experimental investigation of spectrograms as the response of the system in a wide frequency range. Because crack propagation results in energy release in the form of the acoustic wave, it was assumed that the phenomenon is related to fatigue crack propagation. Additionally, differences among the spectrograms were 
determined to determine the crack propagation indicator and distinguish the influence of a crack and natural frequencies on the signal amplitudes. It was observed that, considering the characters of both phenomena-stability in frequency (natural vibration mode) and stability in time (fatigue crack propagation) - it is easy to distinguish them. Additionally, the consecutive fatigue crack evolution can be determined by comparing the crack indicator values. It was observed that the indicator values in the range of from 0.017 to 0.129 were related to the crack, where the base (threshold) values were equal to 0.012 . Therefore, the vibration analyses based on the spectrograms can be applied for the determination of the small crack evolution.

It was also possible to determine the direction of the crack propagation. The amplitudes of a system response phenomenon in a wide range of frequencies were higher and more visible for the spectrograms determined for sensor $S_{4}$ (located close to the notch tip), and then for the sensor $S_{2}$ (located after a stiffener). The same behaviour was also visible for differences in the spectrograms and the crack indicator.

Funding: This research was funded by the Ministry of Science and Higher Education, Poland grant number N504 418637 and the Ministry of Science and Higher Education, Poland-Research Project IUVENTUS PLUS grant number IP2011 035771.

Data Availability Statement: The raw/processed data required to reproduce these findings cannot be shared at this time as the data also forms part of an ongoing study.

Acknowledgments: The author of this work would like to thank to researchers from Air Force Institute of Technology, Warsaw, Poland for their help in this studies. ABAQUS calculations were carried out at the Academic Computer Centre in Gdańsk (Poland).

Conflicts of Interest: The author declares no conflict of interest.

\section{References}

1. Kamsu-Foguem, B. Knowledge-based support in Non-Destructive Testing for health monitoring of aircraft structures. Adv. Eng. Inform. 2012, 26, 859-869. [CrossRef]

2. Towsyfyan, H.; Biguri, A.; Boardman, R.; Blumensath, T. Successes and challenges in non-destructive testing of aircraft composite structures. Chin. J. Aeronaut. 2020, 33, 771-791. [CrossRef]

3. Wu, B.; Wu, G.; Yang, C. Parametric study of a rapid bridge assessment method using distributed macro-strain influence envelope line. Mech. Syst. Signal Process. 2019, 120, 642-663. [CrossRef]

4. Chen, J.; Wang, J.; Li, X.; Sun, L.; Li, S.; Ding, A. Monitoring of temperature and cure-induced strain gradient in laminated composite plate with FBG sensors. Compos. Struct. 2020, 242, 112168. [CrossRef]

5. Udd, E.; Spillman, W.B., Jr. Fiber Optic Sensors: An Introduction for Engineers and Scientists; John Wiley \& Sons: Hoboken, NJ, USA, 2011.

6. Fernández, R.; Gutiérrez, N.; Jiménez, H.; Martín, F.; Rubio, L.; Jiménez-Vicaria, J.D.; Paulotto, C.; Lasagni, F. On the structural testing monitoring of CFRP cockpit and concrete/CFRP pillar by FBG sensors. Adv. Eng. Mater. 2016, 18, 1289-1298. [CrossRef]

7. Mieloszyk, M.; Ostachowicz, W. An application of Structural Health Monitoring system based on FBG sensors to offshore wind turbine support structure model. Mar. Struct. 2017, 51, 65-86. [CrossRef]

8. Chan, T.H.; Yu, L.; Tam, H.Y.; Ni, Y.Q.; Liu, S.; Chung, W.; Cheng, L. Fiber Bragg grating sensors for structural health monitoring of Tsing Ma bridge: Background and experimental observation. Eng. Struct. 2006, 28, 648-659. [CrossRef]

9. Mieloszyk, M.; Majewska, K.; Ostachowicz, W. Application of embedded fibre Bragg grating sensors for structural health monitoring of complex composite structures for marine applications. Mar. Struct. 2021, 76, 102903. [CrossRef]

10. Gebremichael, Y.; Li, W.; Boyle, W.; Meggitt, B.; Grattan, K.; McKinley, B.; Fernando, G.; Kister, G.; Winter, D.; Canning, L.; et al. Integration and assessment of fibre Bragg grating sensors in an all-fibre reinforced polymer composite road bridge. Sens. Actuators A Phys. 2005, 118, 78-85. [CrossRef]

11. Liu, Z.; Liu, X.; Zhu, S.P.; Zhu, P.; Liu, W.; Correia, J.A.; De Jesus, A.M. Reliability assessment of measurement accuracy for FBG sensors used in structural tests of the wind turbine blades based on strain transfer laws. Eng. Fail. Anal. 2020, $112,104506$. [CrossRef]

12. Ren, L.; Li Sr, H.; Zhou, J.; Li, D.S.; Sun, L. Health monitoring system for offshore platform with fiber Bragg grating sensors. Opt. Eng. 2006, 45, 084401. [CrossRef]

13. Bang, H.J.; Kim, H.I.; Lee, K.S. Measurement of strain and bending deflection of a wind turbine tower using arrayed FBG sensors. Int. J. Precis. Eng. Manuf. 2012, 13, 2121-2126. [CrossRef] 
14. Lima, H.F.; da Silva Vicente, R.; Nogueira, R.N.; Abe, I.; de Brito Andre, P.S.; Fernandes, C.; Rodrigues, H.; Varum, H.; Kalinowski, H.J.; Costa, A.; et al. Structural health monitoring of the church of Santa Casa da Misericórdia of Aveiro using FBG sensors. IEEE Sens. J. 2008, 8, 1236-1242. [CrossRef]

15. Marazzi, F.; Tagliabue, P.; Corbani, F.M. Traditional vs innovative structural health monitoring of monumental structures: A case study. Struct. Control Health Monit. 2011, 18, 430-449. [CrossRef]

16. Caponero, M.A.; Dell Erba, D.; Kropp, C. Use of fibre optic sensors for structural monitoring of temporary emergency reinforcements of the church S. Maria delle Grazie in Accumoli. J. Civ. Struct. Health Monit. 2019, 9, 353-360. [CrossRef]

17. Wang, G.; Pran, K.; Sagvolden, G.; Havsgård, G.; Jensen, A.; Johnson, G.; Vohra, S. Ship hull structure monitoring using fibre optic sensors. Smart Mater. Struct. 2001, 10, 472. [CrossRef]

18. Roberts, G.W.; Hancock, C.M.; Lienhart, W.; Klug, F.; Zuzek, N.; de Ligt, H. Displacement and frequency response measurements of a ship using GPS and fibre optic-based sensors. Appl. Geomat. 2021, 13, 51-61. [CrossRef]

19. Wada, D.; Igawa, H.; Tamayama, M.; Kasai, T.; Arizono, H.; Murayama, H.; Shiotsubo, K. Flight demonstration of aircraft fuselage and bulkhead monitoring using optical fiber distributed sensing system. Smart Mater. Struct. 2018, 27, 025014. [CrossRef]

20. Ruzek, R.; Kudrna, P.; Kadlec, M.; Karachalios, V.; Tserpes, K. Strain and damage monitoring in CFRP fuselage panels using fiber Bragg grating sensors. Part II: Mechanical testing and validation. Compos. Struct. 2014, 107, 737-744. [CrossRef]

21. Tserpes, K.I.; Karachalios, V.; Giannopoulos, I.; Prentzias, V.; Ruzek, R. Strain and damage monitoring in CFRP fuselage panels using fiber Bragg grating sensors. Part I: Design, manufacturing and impact testing. Compos. Struct. 2014, 107, 726-736. [CrossRef]

22. Mieloszyk, M.; Skarbek, L.; Krawczuk, M.; Ostachowicz, W.; Zak, A. Application of fibre Bragg grating sensors for structural health monitoring of an adaptive wing. Smart Mater. Struct. 2011, 20, 125014. [CrossRef]

23. Święch, Ł. Calibration of a Load Measurement System for an Unmanned Aircraft Composite Wing Based on Fibre Bragg Gratings and Electrical Strain Gauges. Aerospace 2020, 7, 27. [CrossRef]

24. Gutiérrez, N.; Fernández, R.; Galvín, P.; Lasagni, F. Fiber Bragg grating application to study an unmanned aerial system composite wing. J. Intell. Mater. Syst. Struct. 2019, 30, 1252-1262. [CrossRef]

25. Tsuda, H.; Lee, J.R.; Guan, Y. Fatigue crack propagation monitoring of stainless steel using fiber Bragg grating ultrasound sensors. Smart Mater. Struct. 2006, 15, 1429. [CrossRef]

26. Australian Transport Safety Bureau. How Old Is Too Old? The Impact of Ageing Aircraft on Aviation Safety; Australian Transport Safety Bureau: Canberra, Australia, 2007.

27. Fan, S.; Zhang, A.; Sun, H.; Yun, F. A Local TR-MUSIC Algorithm for Damage Imaging of Aircraft Structures. Sensors 2021, 21, 3334. [CrossRef] [PubMed]

28. Zhong, Y.; Yuan, S.; Qiu, L. Multiple damage detection on aircraft composite structures using near-field MUSIC algorithm. Sens. Actuators A Phys. 2014, 214, 234-244. [CrossRef]

29. Bao, Q.; Yuan, S.; Guo, F. A new synthesis aperture-MUSIC algorithm for damage diagnosis on complex aircraft structures. Mech. Syst. Signal Process. 2020, 136, 106491. [CrossRef]

30. Azuara, G.; Barrera, E.; Ruiz, M.; Bekas, D. Damage detection and characterization in composites using a geometric modification of the RAPID algorithm. IEEE Sens. J. 2019, 20, 2084-2093. [CrossRef]

31. Zhao, X.; Gao, H.; Zhang, G.; Ayhan, B.; Yan, F.; Kwan, C.; Rose, J.L. Active health monitoring of an aircraft wing with embedded piezoelectric sensor/actuator network: I. Defect detection, localization and growth monitoring. Smart Mater. Struct. 2007, 16, 1208. [CrossRef]

32. Briand, W.; Rebillat, M.; Guskov, M.; Mechbal, N. Damage size quantification in aeronautic composite structures based on imaging results post-processing. In Proceedings of the IX ECCOMAS Thematic Conference on Smart Structures and Materials, Paris, France, 8-11 July 2019; pp. 1-12.

33. Ang, J.; Li, H.; Herszberg, I.; Bannister, M.; Mouritz, A. Tensile fatigue properties of fibre Bragg grating optical fibre sensors. Int. J. Fatigue 2010, 32, 762-768. [CrossRef]

34. Yashiro, S.; Okabe, T. Estimation of fatigue damage in holed composite laminates using an embedded FBG sensor. Compos. Part $A$ Appl. Sci. Manuf. 2011, 42, 1962-1969. [CrossRef]

35. Takeda, S.; Aoki, Y.; Ishikawa, T.; Takeda, N.; Kikukawa, H. Structural health monitoring of composite wing structure during durability test. Compos. Struct. 2007, 79, 133-139. [CrossRef]

36. Kocaman, E.S.; Keulen, C.J.; Akay, E.; Yildiz, M.; Turkmen, H.S.; Suleman, A. An experimental study on the effect of length and orientation of embedded FBG sensors on the signal properties under fatigue loading. Sci. Eng. Compos. Mater. 2016, 23, 711-719. [CrossRef]

37. Shen, W.; Yan, R.; Xu, L.; Tang, G.; Chen, X. Application study on FBG sensor applied to hull structural health monitoring. Optik 2015, 126, 1499-1504. [CrossRef]

38. Szebényi, G.; Blößl, Y.; Hegedüs, G.; Tábi, T.; Czigany, T.; Schledjewski, R. Fatigue monitoring of flax fibre reinforced epoxy composites using integrated fibre-optical FBG sensors. Compos. Sci. Technol. 2020, 199, 108317. [CrossRef]

39. Vieira, J.; Morais, O.; Vasques, C.; de Oliveira, R. A laboratorial prototype of a weight measuring system using optical fiber Bragg grating sensors embedded in silicone rubber. Measurement 2015, 61, 58-66. [CrossRef]

40. U.S. Department of Transportation. Helicopter Instructor's Handbook; Federal Aviation Administration, Flight Standards Service; U.S. Department of Transportation: Washington, DC, USA, 2012. 
41. Klimaszewski, S.; Leski, A.; Dragan, K.; Kurdelski, M.; Wrona, M. Helicopter Structural Integrity Program Of Polish Mi-24 Hind Helicopters. In ICAF 2009, Bridging the Gap between Theory and Operational Practice; Springer: Berlin/Heidelberg, Germany, 2009; pp. 263-277.

42. Lombardo, D. Helicopter Structures-A Review of Loads, Fatigue Design Techniques and Usage Monitoring; U.S. Department of Defence: Washington, DC, USA, 1993.

43. Sih, G.C. Elastodynamic Crack Problems; Springer Science \& Business Media: Berlin/Heidelberg, Germany, 1977 ; Volume 4. 